\title{
Body size variation in insects: a macroecological perspective
}

\author{
Steven L. Chown ${ }^{1, *}$ and Kevin J. Gaston ${ }^{2}$ \\ ${ }^{1}$ Centre for Invasion Biology, Department of Botany and Zoology, Stellenbosch University, Private Bag X1, Matieland 7602, South Africa \\ (E-mail:slchown@sun.ac.za) \\ ${ }^{2}$ Biodiversity and Macroecology Group, Department of Animal and Plant Sciences, University of Sheffield, Sheffield S10 2TN, UK \\ (E-mail:k.j.gaston@sheffield.ac.uk)
}

(Received 18 January 2009; revised 31 July 2009; accepted 17 August 2009)

\begin{abstract}
Body size is a key feature of organisms and varies continuously because of the effects of natural selection on the size-dependency of resource acquisition and mortality rates. This review provides a critical and synthetic overview of body size variation in insects from a predominantly macroecological (large-scale temporal and spatial) perspective. Because of the importance of understanding the proximate determinants of adult size, it commences with a brief summary of the physiological mechanisms underlying adult body size and its variation, based mostly on findings for the model species Drosophila melanogaster and Manduca sexta. Variation in nutrition and temperature have variable effects on critical weight, the interval to cessation of growth (or terminal growth period) and growth rates, so influencing final adult size. Ontogenetic and phylogenetic variation in size, compensatory growth, scaling at the intra- and interspecific levels, sexual size dimorphism, and body size optimisation are then reviewed in light of their influences on individual and species body size frequency distributions. Explicit attention is given to evolutionary trends, including gigantism, Cope's rule and the rates at which size change has taken place, and to temporal ecological trends such as variation in size with succession and size-selectivity during the invasion process. Large-scale spatial variation in size at the intraspecific, interspecific and assemblage levels is considered, with special attention being given to the mechanisms proposed to underlie clinal variation in adult body size. Finally, areas particularly in need of additional research are identified.
\end{abstract}

Key words: Bergmann's rule, clinal variation, compensatory growth, frequency distribution, gigantism, ontogeny, Rensch's rule, seasonality, sexual size dimorphism.

\section{GONTENTS}

I. Introduction

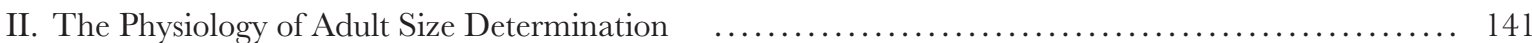

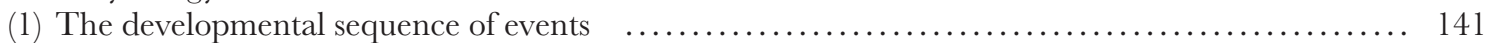

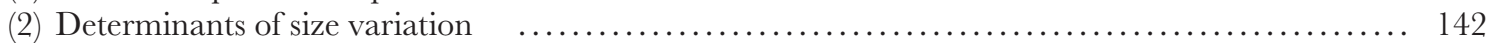

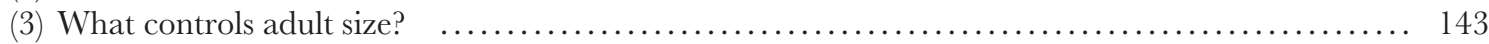

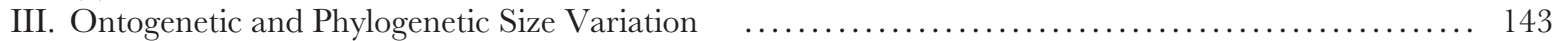

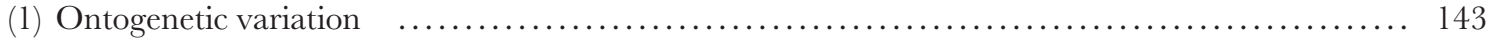

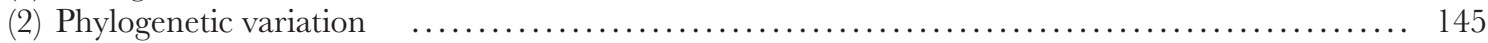

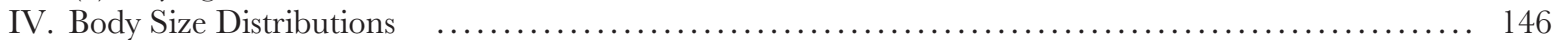

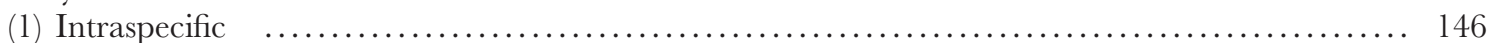

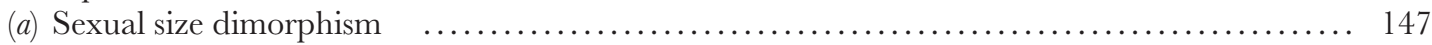

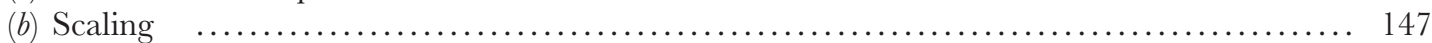

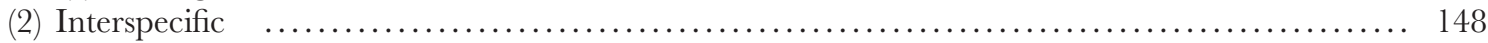

* Address for correspondence: (Tel: +2721 808-2385; Fax: +2721 808-2995; E-mail: slchown@sun.ac.za) 


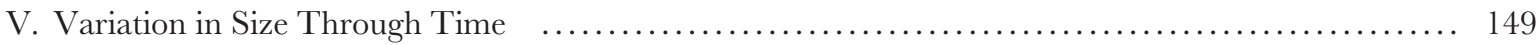

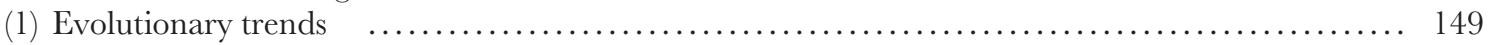

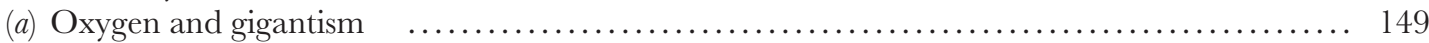

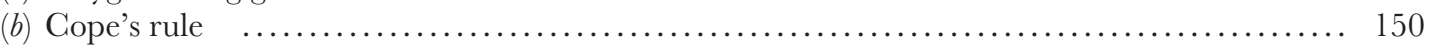

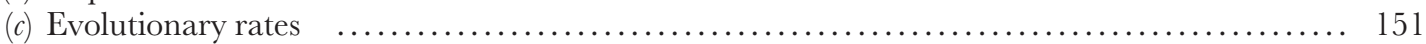

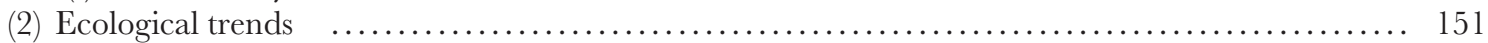

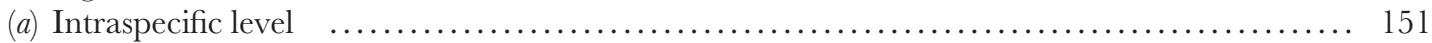

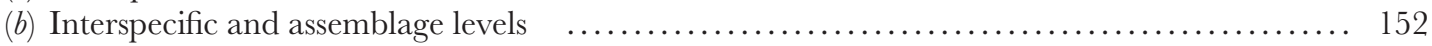

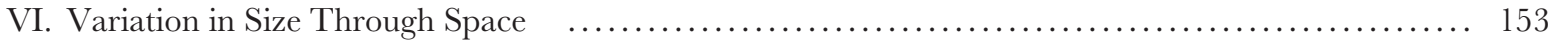

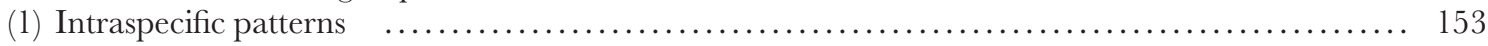

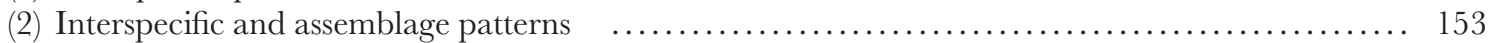

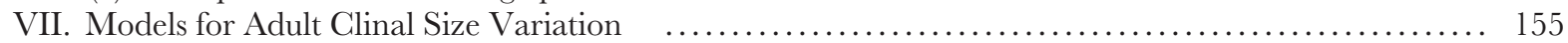

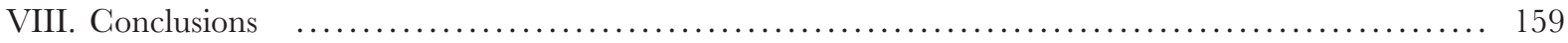

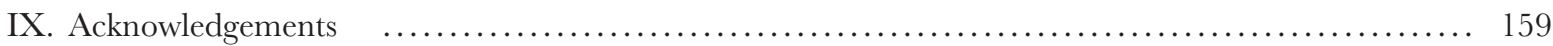

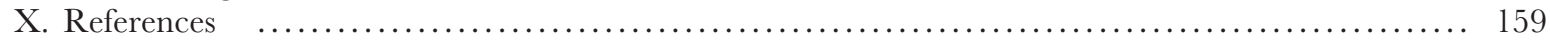

\section{INTRODUGTION}

Body size is one of the most striking features of all organisms. Indeed, it is thought to be documented as frequently by biologists as human age is by reporters (Nee \& Lawton, 1996). The apparency of body size has resulted in a tacit acceptance by many that it can be considered, for all practical purposes, a fixed, or an 'independent', variable in biological studies, strange as this might seem to evolutionary ecologists. Often this perspective is a matter of convenience, since so many physiological, life-history, and ecological traits are strongly related to size, and because, with due care (Hayes \& Shonkwiler, 2006), these traits may be predicted from a measure of size. However, some recent approaches treat size as a fixed variable that has consequences for such other traits (see review in Brown et al., 2004). By contrast, much of life-history theory considers size to be a continuously varying trait dependent on a variety of factors operating at different stages in an individual's life, and their integration (Roff, 1981, 2002; Bede, McNeil \& Tobe, 2007). Most prominent amongst the proximate, physiological factors are differences in growth rate and the duration of important periods during juvenile growth, the regulatory basis for this variation, and regulatory differences in the rate and duration of cell proliferation (Nijhout, 2003; Emlen \& Allen, 2004; Edgar, 2006; Nijhout, Davidowitz \& Roff, 2006; Mirth \& Riddiford, 2007). Amongst the ecological factors are the size-dependencies of production and mortality rates and the differences between capital and income breeders (Kirkendall \& Stenseth, 1985; Kozłowski, Czarnołêski \& Dañko, 2004; Teder, Tammaru \& Esperk, 2008). These size-dependencies interact with the physiology of the animal, which in turn may also be related to genome size, cell size and membrane properties (Kozłowski, Konarzewski \& Gawelczyk, 2003; Hulbert, 2003, 2008). The size-dependencies are also affected by the animal's environmental circumstances, which may alter mortality and production rates at various stages (Roff, 2002). Hence, natural selection continuously sculpts body size, which, nonetheless, tends also to be phylogenetically conservative (Gaston \& Blackburn, 2000).
What form the size frequency distributions of populations and assemblages take as a consequence of these interactions, and how and why these distributions vary over large spatial and temporal scales form a major component of macroecology (Brown, 1995; Gaston \& Blackburn, 2000; Brown et al., 2004; Diniz-Filho et al., 2007; Gaston et al., 2008). Indeed, given the frequently marked relationships between body size and energy use, abundance, and geographic range size (e.g. Brown et al., 2004; E.P. White et al., 2007), body size variation has long been, and remains of central concern to macroecologists (Brown, 1995; Gaston \& Blackburn, 1996; Blackburn \& Gaston, 1999, 2001; Brown et al., 2003; Olson et al., 2009). In essence, macroecology is concerned with understanding the division of food and space among species at large spatial and temporal scales (Brown \& Maurer, 1989), or, alternatively, with understanding the distribution and abundance of organisms at large spatial and temporal scales (Gaston \& Blackburn, 2000). Although macroecological investigations encompass a wide variety of theoretical and empirical approaches (Brown, 1995, 1999; Blackburn \& Gaston, 1998, 2003), often a distinction is drawn between univariate, bivariate and multivariate perspectives, and integration follows from joint consideration of the insights obtained from each (e.g. Gaston \& Blackburn, 2000; McGill, 2003; Hui \& McGeoch, 2008; E.P. White et al., 2007; Storch et al., 2008).

Given the extraordinary diversity of insects (Gaston, $1991 b$ ) and their preponderance amongst animals, at least at the species level, for any model or hypothesis which seeks to explain large-scale patterns in or concerning the evolution of size to claim wide applicability or primacy, it must apply as much to insects as to any other group of organisms. To assess the validity for such claims requires knowledge of the hypotheses and models in question as well as the empirical information on the insects. Unlike groups such as birds and mammals, for which macroecological patterns of body size variation and their underlying mechanisms have been well documented (Gaston \& Blackburn, 2000; Smith et al., 2004; Millien et al., 2006), in insects several broader scale patterns and their likely underlying mechanisms remain 
poorly synthesized. Here, we adopt a largely univariate macroecological perspective in critically reviewing a variety of empirical patterns in insect size variation, their likely mechanisms, and their downstream consequences. The univariate perspective most commonly concerns the form of and mechanisms underlying frequency distributions (Morse, Stork \& Lawton, 1988; Hanski \& Cambefort, 1991; Blackburn \& Gaston, 1994b; Gaston \& Blackburn, 2000), the ways in which these distributions (or their central tendencies) vary over space (e.g. Ashton, Tracy \& De Queiroz, 2000; Millien et al., 2006; Greve et al., 2008) and time (e.g.Jablonski, 1997; Kingsolver \& Pfennig, 2004), and the extent to which variation shows a phylogenetic signal (e.g. Smith et al., 2004; Diniz-Filho et al., 2007).

As is common in macroecology, we accept that the explanations for many patterns lie at lower levels in the biological hierarchy, whilst the consequences thereof may be most visible at higher levels (Gaston \& Blackburn, 2000, see also Eldredge, 1986). Thus, physiological regulation of growth and development, in the context of life history, must necessarily play critical roles in setting final size, as well as allometric variation (Shingleton et al., 2007). Without some comprehension of the biochemical and physiological basis of size determination in insects, and without considering the life-history consequences of size variation, many large-scale patterns of body size variation cannot readily be comprehended. Therefore, we begin with a brief overview of the biochemical and physiological bases of size determination, and draw on insights from life-history theory wherever appropriate. However, these topics are largely not the subject of the present review, and are wellrepresented in a large and growing literature (see e.g. reviews by Sehnal, 1985; Nijhout, 1994, 2003; Oldham et al., 2000; Roff, 2001, 2002; Davidowitz, D'Amico \& Nijhout, 2003; Emlen \& Allen, 2004; Dubrovsky, 2005; Gäde \& Hoffmann, 2005; Edgar, 2006; Emlen, Lavine \& Ewen-Campen, 2007; Mirth \& Riddiford, 2007; Angilletta, 2009).

\section{THE PHYSIOLOGY OF ADULT SIZE DETERMINATION}

Although some, especially earlier, research concerned the physiology of adult size determination in nonholometabolous insects (see reviews in Nijhout, 1994, 2003), much recent work has focused on holometabolous species, specifically Drosophila melanogaster (Diptera) and Manduca sexta (Lepidoptera, Sphingidae). Different aspects of the determination of final adult size have been considered in these two species. In some cases it is clear that the mechanisms are similar, but in others this has not yet been verified. For example, the sequence of endocrine events leading up to critical weight are much better defined in Manduca sexta and other Lepidoptera than they are in Drosophila melanogaster (Mirth \& Riddiford, 2007). Moreover, the extent to which the physiological control mechanisms of size, operating at both the local cellular and higher levels, can be generalised to other insect species is not yet fully established (Nijhout, 2003; Parker \& Johnston, 2006), but presumably they generalize in their most significant aspects.

\section{(1) The developmental sequence of events}

Because of much recent work on Manduca sexta that concerns both physiological and evolutionary aspects of body size variation (Nijhout, 1975; D'Amico, Dawidowitz \& Nijhout, 2001; Davidowitz et al., 2003; Davidowitz, D'Amico \& Nijhout 2004; Davidowitz, Roff \& Nijhout, 2005; Davidowitz \& Nijhout, 2004; Nijhout et al., 2006; Kingsolver, 2007), in the context of this review it is most useful to focus on events during the growth and development of this species. Manduca sexta typically has five larval instars (though see Kingsolver, 2007), and size within each is constrained by the sclerotized head capsule and by the soft integument's epicuticle. The initial mass of each instar is a multiple (usually constant) of that of the former instar, more generally known as Dyar's constant or rule. The size of the first instar is determined by egg size. In other species, egg size varies among populations, as it does among species. It is also phenotypically plastic, being sensitive to day length, temperature, nutrition and conditions experienced by the adult and also by the juvenile stage of the egg-laying adult, and it also responds to selection (Azevedo, French \& Partridge, 1996; Ernsting \& Isaaks, 1997, 2000; Blanckenhorn, 2000a; García-Barros, 2000; Fischer, Zwaan \& Brakefield, 2002; Fischer et al., 2003, Fischer, Bauerfeind \& Fiedler, 2006; Stillwell \& Fox, 2005; Fox \& Czesak, 2006; Homeny \& Juliano, 2007; Steigenga \& Fischer, 2007). The growth ratio at each moult is determined by both cell size and number. Moulting is triggered by a well-known set of hormonal events including increases in prothoracicotrophic hormone (PTTH) and ecdysteroids in the presence of juvenile hormone $(\mathrm{JH})$.

In the last larval instar of Manduca sexta the typical sequence of events changes (Fig. 1). JH inhibits the secretion of PTTH and ecdysteroids during the early portion of the instar. Thereafter, JH secretion by the corpora allata ceases and the levels of juvenile hormone esterase (JHE), which breaks down JH, increase. When JH disappears, PTTH and ecdysteroid secretion are disinhibited. However, PTTH is only secreted during a photoperiodic gate that is controlled by a photoperiodic clock (this is not the case in Drosophila melanogaster-see Edgar, 2006). If this $8 \mathrm{~h}$ time window, which recurs daily, is closed, PTTH secretion does not occur and up to $16 \mathrm{~h}$ may pass before PTTH is secreted. Once this happens, PTTH stimulates ecdysteroid secretion, which then causes the larva to stop feeding, clear its gut of all content, and to wander in search of a suitable pupation site. Because pupae do not feed, the final mass of the last larval instar usually determines adult size. In many insect species adult feeding may lead to additional mass gain even though adult linear dimensions are fixed and, in a few others, circumstances during the pupal stage may affect adult mass (Fischer \& Fiedler, 2002).

The larval mass at which JH secretion ceases is of considerable biological significance, and is termed the critical 


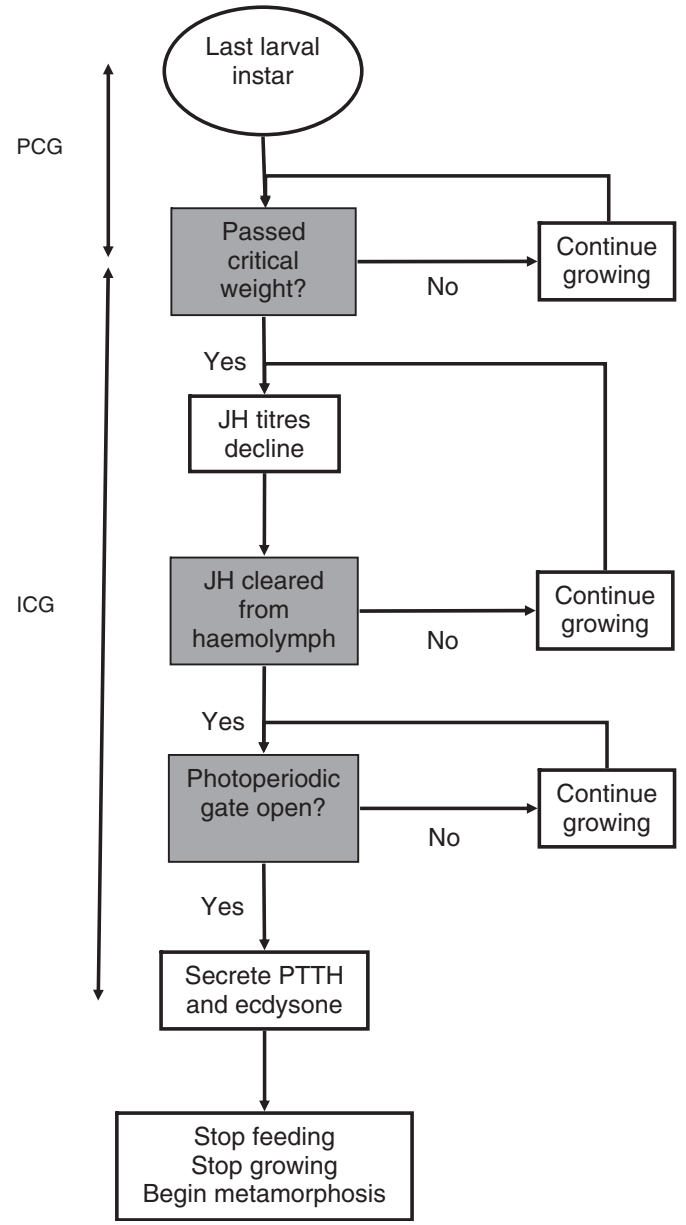

Fig. 1. The mechanisms controlling size in the final instar larvae of the tobacco hornworm, Manduca sexta (Lepidoptera, Sphingidae). The physiological points determining the timing of the cessation of growth are indicated by the shaded boxes. The extent of growth between these points determines final size. PCG $=$ growth prior to critical weight, $\mathrm{ICG}=$ interval to cessation of growth, $\mathrm{JH}=$ juvenile hormone, PTTH = prothoracicotrophic hormone. Redrawn from Nijhout et al. (2006).

weight (Nijhout et al., 2006). This is not to be confused with the minimal viable weight, that below which individuals do not survive to pupation (Nijhout, 1975; Mirth \& Riddiford, 2007). Once JH secretion ceases, the larva is irrevocably committed to a sequence of events that are independent of further growth or nutrition. The interval between attainment of critical weight and the secretion of PTTH (meaning full clearance of $\mathrm{JH}$ ) is also of considerable significance in the context of adult size, and is known as the interval to the cessation of growth (ICG) (Davidowitz et al., 2004). However, because the mechanisms linking critical size to increases in ecdysteroids have not been as well elucidated in other species, it has been suggested that the interval be more generally known as the terminal growth period (TGP) (Shingleton et al., 2007). This usage may also facilitate models of static allometry that include investigations of the growth and development of the imaginal discs, which may differ from overall size in the length of their terminal growth period (Shingleton, Mirth \& Bates, 2008).

\section{(2) Determinants of size variation}

Adult size variation can clearly be determined by variation in the number of larval instars, the growth rate and duration of each (affecting the size increment at each moult), and growth rate and the timing of events during the last larval instar. In many species larval instar number is fixed, and indeed a general phyletic trend of reduced instar number and increased instar growth increment exists (Nijhout, 1994). However, growth rates and instar duration can be labile, as can instar number in some species (e.g. Shafiei, Moczek \& Nijhout, 2001; Tammaru et al., 2004; Esperk et al., 2007; Kingsolver, 2007; Etilé \& Despland, 2008), although growth rate rarely reaches the physiological maximum (see Section III.1). In Manduca sexta, the final size of the last larval instar depends on five factors: initial size (which depends on egg size), growth rate, critical weight, the time required to clear $\mathrm{JH}$, and the timing of the photoperiodic gate for PTTH secretion (Nijhout et al., 2006). These factors all respond to selection (D'Amico et al., 2001; Davidowitz et al., 2005). The five factors can be simplified to three critical parameters that explain well most of the variation in size among different M. sexta strains (Nijhout et al., 2006): critical weight (which is linearly related to growth increment), growth rate, and the ICG.

Among the many factors that induce phenotypic size variation, nutrition and temperature are most significant. Diet (quality and amount) affects growth rate, which in turn affects instar size. A decline in instar size on poor diets eventually leads to a lower critical weight. Diet quality also affects growth rate before and during the ICG, in the last larval instar, but importantly does not affect the duration of the ICG (Davidowitz et al., 2004; Davidowitz \& Nijhout, 2004). Temperature has a positive effect on growth rate, and also on the rate of biochemical reactions. This means that at higher temperatures not only is growth rate higher, but the rate at which $\mathrm{JH}$ is cleared by JHE increases, which in turn reduces the duration of the ICG (Davidowitz et al., 2004, 2005). By contrast, critical weight is insensitive to temperature (Davidowitz \& Nijhout, 2004). Total development time (larval duration) also declines exponentially with temperature. These differential responses to temperature and diet quality of the factors determining final size have considerable significance for understanding spatial and temporal variation in adult size, and we will return to them in Section VII.

Although much of the focus in $M$. sexta has been on the influence of diet quality and temperature on adult size variation, which can go a long way to explain patterns of size variation seen under laboratory (Atkinson, 1994) and field circumstances, day length may also have significant effects. Several studies have shown that egg size variation may be determined by day length, and that this interacts with other factors to influence egg size (e.g. Ernsting \& Isaaks, 2000). Moreover, whether individuals find themselves at the start 
or end of the growing season, as adjudicated by day length, has a substantial effect on the extent to which growth rate is altered, so influencing size and other factors such as static allometry (e.g. Gotthard, Nylin \& Wiklund, 1999, 2000; Margraf, Gotthard \& Rahier, 2003; Plaistow et al., 2005).

\section{(3) What controls adult size?}

Size is likely to be under both local and more general proximate control. In $D$. melanogaster nutrition-dependent growth is controlled by insulin/insulin-like growth factor signalling (IIS), and has been the subject of much recent research (reviewed in Edgar, 2006; Mirth \& Riddiford, 2007; see also Emlen et al., 2007). Insulin-like peptides influence both growth rate and final adult size. The target of rapamycin (TOR) protein kinase is probably the most significant growthregulatory target of insulin signalling, and again has been well studied. It responds to levels of ATP and amino acids, and is also sensitive to oxygen levels (as is growth rate and, in some species, adult size-see Harrison et al., 2006). How the feedbacks operate between nutrition, IIS and TOR is a rapidly moving research field. The locus of nutrient sensing is especially significant, probably also involving the transcription factor Foxhead Box, class O (FOXO), the fat body, prothoracic gland, and imaginal discs. Juvenile hormone and ecdysteroids are likely also to play a role in the feedback. Indeed, Layalle, Arquier \& Léopold (2008) have recently demonstrated in $D$. melanogaster that if the activity of TOR is reduced in the prothoracic gland, the ecdysone peak that signals the end of larval development no longer occurs. In consequence, the growth period is prolonged and size increases. However, much remains to be understood about how critical weight is assessed, how the relative significance of cell size and number is regulated, and how adult size is finally determined (Edgar, 2006; Mirth \& Riddiford, 2007; Shingleton et al., 2008).

\section{ONTOGENETIC AND PHYLOGENETIC SIZE VARIATION}

\section{(1) Ontogenetic variation}

Body mass and a characteristic linear dimension, such as head length or elytron length (e.g. Kaspari \& Weiser, 1999), are often used interchangeably as measures of body size in insects. Although mass and linear dimensions may be strongly related (mass $^{0.33} \approx$ length) (Hódar, 1996; Benke et al., 1999; Mercer et al., 2001; Powell \& Franks, 2006), this need not always be so. Given constant linear dimensions, adult mass may vary depending on age, season, and the feeding and reproductive status of an individual. At times, such variation may lead to fundamental differences in the shape of body size frequency distributions assessed using mass and a linear dimension for the same population, even when measurement has been temporally and spatially constrained. For example, in both the apionid weevil Setapion provinciale and the wasp Trichilogaster acaciaelongifoliae (Pteromalidae) the body size frequency distributions differ substantially depending on whether length or mass is measured (Fig. 2).

Likewise, during ontogenetic growth, mass increases, whilst many linear dimensions often remain fixed as a consequence of cuticular sclerotization (Sehnal, 1985; Strobbe \& Stoks, 2004; Nijhout et al., 2006). Such differential size increases may also be responsible for variation in the form and central tendency of size frequency distributions based on mass versus linear dimensions. They also have a variety of physiological consequences. The need for moulting is obviously one of the most significant given the physiological sequence of events required and the elevated risk of mortality. However, less fully appreciated is a probable reduction in the safety margin for gas exchange, which may, in turn, also account for the need to moult (Greenlee \& Harrison, 2005): cuticle-lined tracheae and spiracles remain at a fixed size whilst tissue mass increases. However, the extent of this change in safety margin depends also on the capacity for tracheal ventilation of the species concerned, which might more than compensate for a reduced margin associated with fixed tracheal and spiracular sizes (Greenlee \& Harrison, 2004; Harrison, Lafreniere \& Greenlee, 2005). These interactions are important to consider when size variation associated with historical fluctuations in atmospheric oxygen concentration is being investigated.

During ontogeny, the increase in size from egg to adult can be more than two orders of magnitude. Typically, this variation has substantial implications for the resources used by growing individuals, often entailing fundamentally different approaches to acquisition at different life stages (e.g. Gaston et al., 1991). Ontogenetic changes in insect body size also affect the kinds of predators that feed on different stages or instars. In anomalous emperor moth Imbrasia belina caterpillars the early instars are eaten by small predators such as insects and gleaning birds, the later instars by a variety of insectivorous birds, and the last instar by reptiles, mammalian carnivores and humans (Gaston, Chown \& Styles, 1997).

Variation in size amongst individuals of a given species at a given life stage can also be marked. In many social species, size variation is determined by caste membership. Even within castes, variation may be substantial. More extreme cases include leaf-cutter ants Atta spp. and army ants Eciton hamatum, where workers range from 0.0025 to $0.0206 \mathrm{~g}$, and from 0.0017 to $0.027 \mathrm{~g}$, respectively (Feener, Lighton \& Bartholomew, 1988; Roces \& Lighton, 1995). Some of this variation is a consequence of food availability to juvenile stages (Emlen \& Nijhout, 2000; Peat et al., 2005).

Within a season, final adult size, and therefore the form of size-frequency distributions, is strongly dependent on interactions among time constraints, resource allocation to growth and/or reproduction, mortality, physiological costs (such as those associated with oxidative damage), ageing, and food quality (Nylin \& Gotthard, 1998; Blanckenhorn, 1999; Cichoñ \& Kozłowski, 2000; Scriber, 2002; De Block \& Stoks, 2008). In several species, despite initially poor resource conditions, elevation of growth rate occurs such 
A

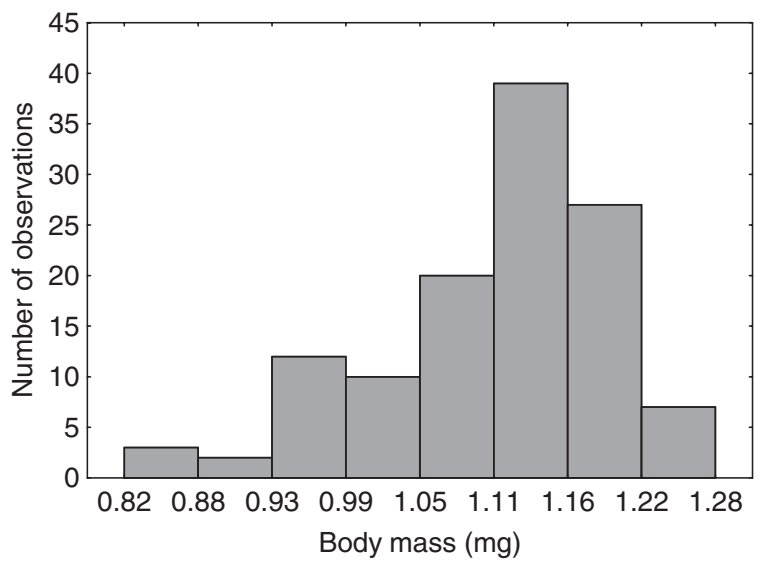

C

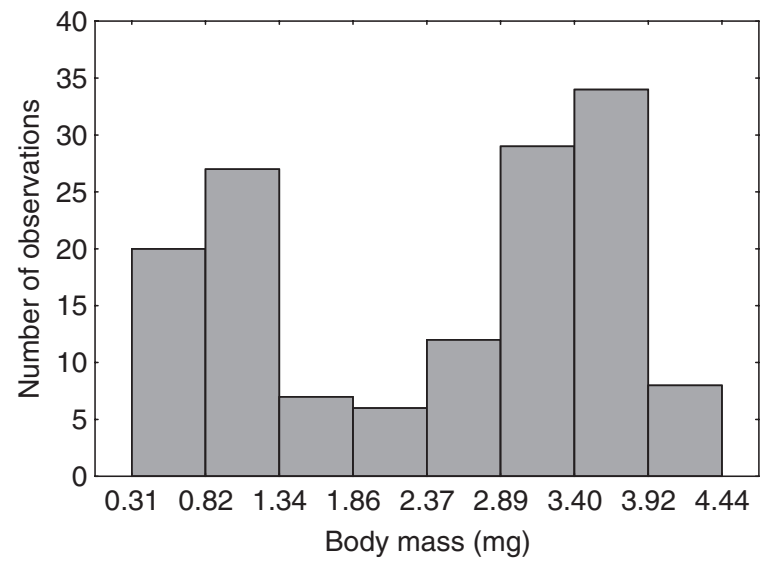

B

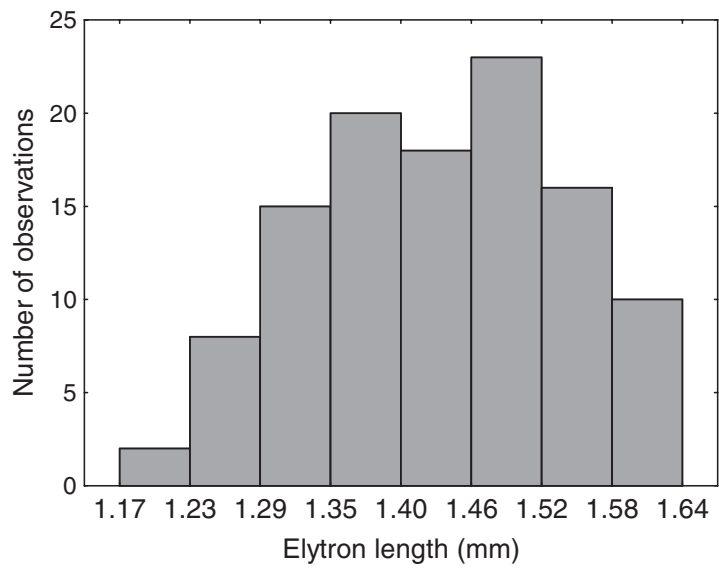

D

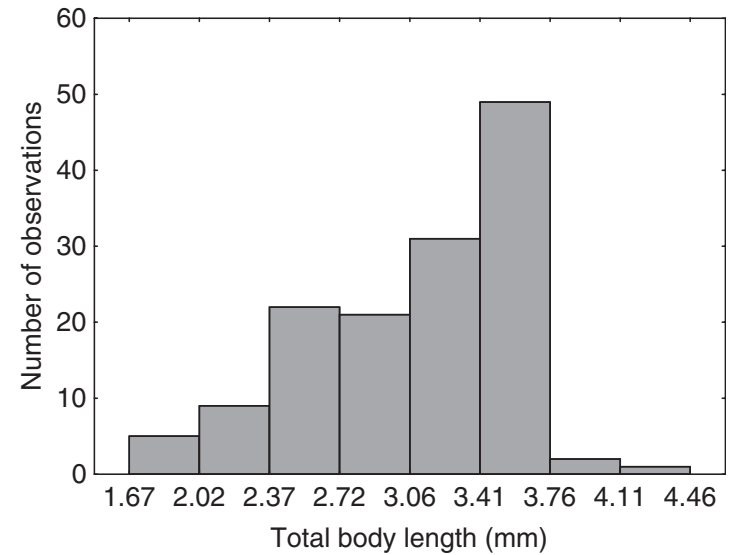

Fig. 2. Body size frequency distributions for: (A, B) Setapion provinciale (Coleoptera, Apionidae) and (C, D) Trichilogaster acaciaelongifoliae (Hymenoptera, Pteromalidae) based on both body mass and linear dimensions. Note the difference in the form of the distributions. In panel C, the bimodality arises from the much lighter males and heavier females. Redrawn from Gouws (2007).

that the final body sizes of adults show much less variation than might otherwise have been the case (Nylin \& Gotthard, 1998; Gotthard, 2004, Gotthard et al., 1999, 2000; Margraf et al., 2003; Strobbe \& Stoks, 2004). Nonetheless, additional growing time does not always serve to increase size (Kause et al., 2001; Berner, Blanckenhorn \& Körner, 2005), and may also be sex dependent (Plaistow et al., 2005; Esperk et al., 2007; Etilé \& Despland, 2008). Resource quality and the presence of predators often play a significant role in determining final size, whether this size is attainable given seasonal time constraints, and what the costs thereof might be (Scriber \& Lederhouse, 1992; Scriber, 2002; Berner et al., 2005; Stoks et al., 2006b; De Block, McPeek \& Stoks, 2008; Röder, Rahier \& Naisbit, 2008). Although increased growth rates might be able to compensate for linear dimensions, mass may nonetheless be reduced under time constraints (Nylin \& Gotthard, 1998; Strobbe \& Stoks, 2004). At least in income breeders, adults can gain mass by feeding, reducing the significance of low emergence mass.
For capital breeders, emergence mass is set by resource allocation in the immature stages. This difference between income and capital breeders affects the relationship between final size and size variation because in the latter a linear increase in fecundity with size is likely, whilst in the former behavioural performance constrains maximum size (Teder et al., 2008). These differences have implications for the overhead threshold model for the relationship between age and size at maturity (see Day \& Rowe 2002).

Compensatory (or catch-up) growth is associated with intrinsic physiological costs, such as developmental errors and oxidative damage, and extrinsic costs such as increased exposure to predators and/or parasitoids (Nylin, Gotthard \& Wiklund, 1996; Arendt, 1997; Mangel \& Munch, 2005; Stoks, De Block \& McPeek, 2006a; De Block \& Stoks, 2008). Hence, growth rates are often less than the physiological maximum. A recent life-history approach, incorporating the mortality consequences of body size and physiological damage has demonstrated the circumstances under which 
compensatory growth will tend to arise (Mangel \& Munch, 2005). In the absence of selection on components of growth and damage, it is likely to be rare. The relative likelihood of different forms of compensation is long-term $>$ short-term $\approx$ short-term + long-term > overshooting.

Size variation is not only a consequence of interactions between the genotype and proximate, environmental effects, but also has a strong phylogenetic component (e.g. Read \& Harvey, 1989; Smith et al., 2004). Somewhat surprisingly, this phylogenetic component has not been extensively explored (but see e.g. Brändle, Stadler \& Brandl, 2000).

\section{(2) Phylogenetic variation}

Across the insects as a whole, the smallest species is apparently the mymarid egg-parasitic wasp Dicopomorpha echmepterygis, with an adult male body length of approximately $139 \mu \mathrm{m}$, and females 40\% larger (Gahlhoff, 1998). However, it is likely that there are yet smaller species still to be found, given that most species of insects remain undescribed, the typically negative relationship between mass and date of description in insects (Blackburn \& Gaston, 1994a; Gaston \& Blackburn, 1994), and that this species was not described until 1997. Five beetle species are thought to be the largest insect species: the cerambycid Titanus giganteus $(167 \mathrm{~mm})$, the elephant beetles Megasoma elephas $(137 \mathrm{~mm})$ and Megasoma actaeon $(135 \mathrm{~mm})$, and the goliath beetles Goliathus goliatus and G. regius (110 mm) (Williams, 2001). This gives a range of body lengths for adult insects of three orders of magnitude. Across the beetles alone, species body lengths may vary to a similar extent, with the feather-winged beetles (Ptiliidae) being as small as $250 \mu \mathrm{m}$ (Gahlhoff, 1998).

The reliance on length, rather than mass, as a measure of insect body size reflects a general practical constraint. Collection and storage methods often limit opportunities for the direct determination of fresh body masses, and most studies of macroecological patterns in insect body size have thus employed measures of characteristic linear dimensions. Nonetheless, direct body mass measurements for insects are common, and there is substantial interspecific mass variation across the group. It is at least six orders of magnitude, ranging from the thrips Apterothrips apteris on Marion Island at $0.00004 \mathrm{~g}$ (Mercer et al., 2001) to the scarab beetle Circellium bacchus, which can weigh in excess of $10 \mathrm{~g}$ (Chown et al., 1995). However, globally the range is probably seven orders of magnitude given the small size of some mymarid wasps. This range is greater than the approximately four orders of magnitude spanned by birds (Blackburn \& Gaston, 1994b), similar to that of mammals (Smith et al., 2004), but smaller than that of fish, which range from likely milligram masses (Kottelat et al., 2006) to the basking and whale sharks which weigh several thousands of kilograms, so spanning eight or more orders of magnitude.

Along with a number of life-history traits, the body size of animals tends to show a strong signal associated with phylogeny and/or taxonomic grouping above the species level (i.e. among genera, families and orders) (Gaston \& Blackburn, 2000). This also appears to be true of the insects, although empirical studies are limited. Studies of individual orders in particular regions have found that substantial variation is partitioned above the species level (Brändle et al., 2000). Using body masses from an updated database constructed to examine variance partitioning in physiological traits (much of which occurs at family and genus levels; Chown, Addo-Bediako \& Gaston, 2002), and including only those taxa for which data were available for two or more subtaxa, taxonomic order accounts for $3 \%$ of the variation in body size, family for $38 \%$, genus for $39 \%$, and the remaining variation is partitioned at the species level. However, these data represent only 212 species and five orders. If the genus level is ignored and the same constraint is set, 590 species in 10 orders can be examined. In this case, order accounts for $15 \%$ of the variation, family for $23 \%$, and the remaining $62 \%$ is partitioned at the genus and species level. Overall, this partitioning makes intuitive sense, given that within orders such as the Orthoptera, Coleoptera, Hemiptera, Hymenoptera and Lepidoptera, species take on a wide range of sizes (Fig. 3), whilst within a given family size ranges are smaller.

The benefits of large body size have been widely explored, and are known to include greater fecundity in females, access to mates in males and resource sequestration advantages (Honík, 1993; Lighton, Quinlan \& Feener, 1994; Parker \& Simmons, 1994; Blanckenhorn, 2000b; Rivero \& West, 2002). These benefits can be affected by patterns of resource acquisition and allocation (Kemp \& Alcock, 2003), and by differences among the sexes in the benefits of large size, their responses to selection, and correlations among these responses (e.g. Molumby, 1997; Alcock, Simmons \& Beveridge, 2006; Fox \& Czesak, 2006). For example, in the bruchid Stator limbatus fecundity selection is the main source of selection on female and male size on a host on which larval mortality is low. By contrast, on a poor host, selection via a female size, egg size, fitness path offsets the reduction in fecundity selection of female size, but not on the size of males (Fox \& Czesak, 2006).

The benefits of small size have not been examined so thoroughly. These may include reduced viability costs of growth and development, enhanced agility and reduced detectability, lowered maintenance energy costs, reduced heat stress, reduced costs of reproduction, and increased scramble competitive ability (Blanckenhorn, 2000b, 2005; Moya-Laraño, El-Sayyid \& Fox, 2007). The life-history costs of large size may be difficult to detect because they only become evident under stressful conditions, large individuals may die early, or a platykurtic function may link size to fitness (Reim, Teuschl \& Blanckenhorn, 2006; Teuschl, Reim \& Blanckenhorn, 2007). Reim et al. (2006) examined two contrasting metabolic hypotheses concerning the relative costs of a given body size. Large individuals could either be advantaged because they have relatively high energy use efficiency owing to the negative scaling of mass-specific metabolic rate (see also Blanckenhorn, Fanti \& Reim, 2007b), or disadvantaged because they have higher absolute energy requirements (Blanckenhorn, 2005). Using 

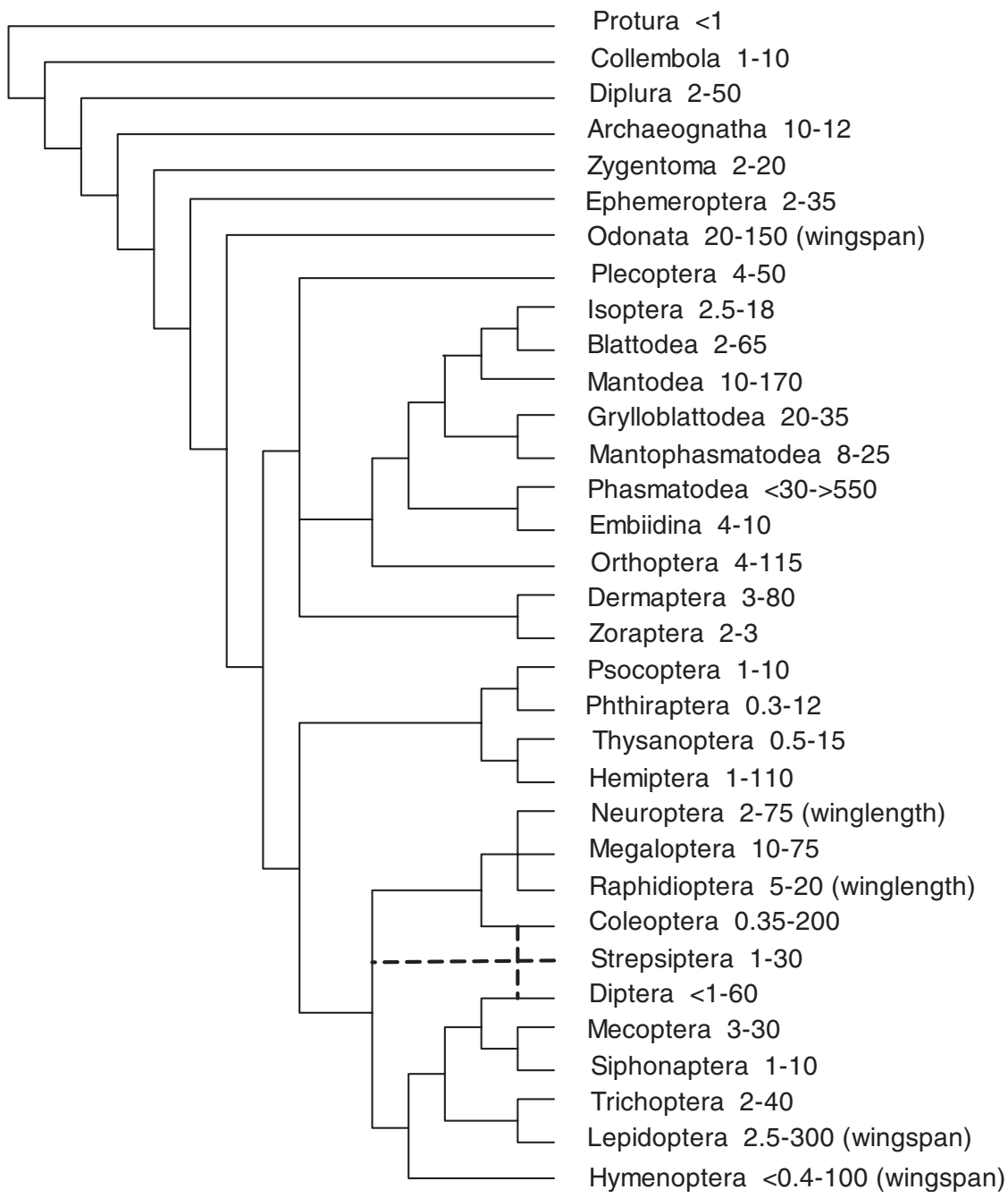

Fig. 3. Estimates of the minimum and maximum adult body lengths ( $\mathrm{mm}$ ) of species in different insect orders and close relatives, superimposed on a cladogram of their postulated relationships based on combined morphological and nucleotide sequence data. Broken lines indicate uncertain relationships. Cladogram from Gullan \& Cranston (2005). Body size data from a variety of sources (available from the authors on request).

yellow dung flies Scathophaga stercoraria as model organisms the relative efficiency hypothesis could not be rejected (Reim et al., 2006). In a further study of the same species, Teuschl et al. (2007) showed that large flies suffered greatest mortality under extreme food limitation, and were most susceptible to winter frost because of their long development times.

\section{BODY SIZE DISTRIBUTIONS}

\section{(1) Intraspecific}

Despite a large literature on the factors influencing final adult size in insects, the body size frequency distributions of the individuals of particular species have been poorly documented. Moreover, knowledge thereof has typically resulted as a by-product of studies with other goals in mind.
Thus, many of the factors confounding the interpretation of body size frequency distributions, such as sample size and the choice of class size (or the width of classes used for constructing the frequency distribution) (Loder, Blackburn \& Gaston, 1997) have not been considered in these studies. A range of shapes nonetheless characterise these distributions. In Centris pallida bees, intraspecific variation in head width is positively skewed (Alcock, 1984). In the longicorn Phoracantha semipunctata, elytron length does not deviate significantly from a normal distribution (Hanks, Paine \& Millar, 2005), and this seems also to be the case in two coccinellid species (Evans, 2000), and in Drosophila melanogaster (David et al., 1997). In adult Anopheles mosquitoes, wing length frequency distributions are significantly negatively skewed (Lounibos, 1994). Frequency distributions of masses seem to be equally rare. In six species of Bombus, size frequency distributions appear positively skewed (Peat et al., 2005). Similarly, the size 
distributions of adult leaf-cutter and army ants are distinctly non-normal, though this reflects the range of castes within each of the species (Feener et al., 1988).

The most comprehensive single analysis yet undertaken of intraspecific body size frequency distributions in insects included 16 species, used both mass and a characteristic linear dimension as measures of size, and was careful to maintain sample sizes in the region of 100 individuals and to give appropriate consideration to size class choice (Gouws, 2007) (Fig. 2). For mass, nearly half of the distributions were significantly positively skewed, although log-transformation removed the skew in many cases. The remainder of the distributions showed little skew and were approximately normal. In the case of length, only two species showed a significant positive skew in their size frequency distributions. In the remainder, skew was either negative (two species) or not significant.

\section{(a) Sexual size dimorphism}

Although intraspecific body size frequency distributions often do not reveal sexual size dimorphism (SSD), males typically are smaller than females in insects (Fairbairn, 1997; Blanckenhorn et al., 2007a). The opposite pattern is relatively uncommon (Teder \& Tammaru, 2005), but is known from species such as the yellow dung fly (Kraushaar \& Blanckenhorn, 2002) and the seed-feeding beetle Stator limbatus (Chrysomelidae: Bruchinae) (Stillwell \& Fox, 2005). Moreover, in a range of species there is substantial male size polymorphism (in polymorphic ants and some other social Hymenoptera it is the females that are variable; Emlen \& Nijhout, 2000). Intraspecific variation in SSD may well be a consequence of adaptive canalization of reproductive traits (Fairbairn, 2005).

Among species, it is commonly found that sexual size dimorphism increases with size when males are the larger sex, but declines with size when females are larger; this has been formalized as Rensch's rule (Abouhief \& Fairbairn, 1997; Fairbairn, 1997; Blanckenhorn, 2000b). At the intraspecific level, this rule has been found in some species (Fairbairn, 2005). However, at this level, among-population SSD typically does not conform to the rule (Blanckenhorn et al., 2006), and environmental conditions affect the degree rather than direction of SSD, often as a consequence of sexrelated differences in growth and instar number (Teder \& Tammaru, 2005; see also Esperk et al., 2007; Etilé \& Despland, 2008). Where Rensch's rule is found, it seems likely that greater plasticity in males than in females, rather than sexual selection, might account for variation in sexual size dimorphism among populations (Fairbairn, 2005).

Sex-related differences in plasticity may also be the mechanism underlying a geographic version of Rensch's rule, whereby latitudinal clines in males are steeper than those in females (Blanckenhorn et al., 2006). This link between clinal size variation (often termed Bergmann's rule-see below) and differential size variability among the sexes has not been well explored and the reasons for it remain obscure. In addition to variation in phenotypic plasticity, the link may

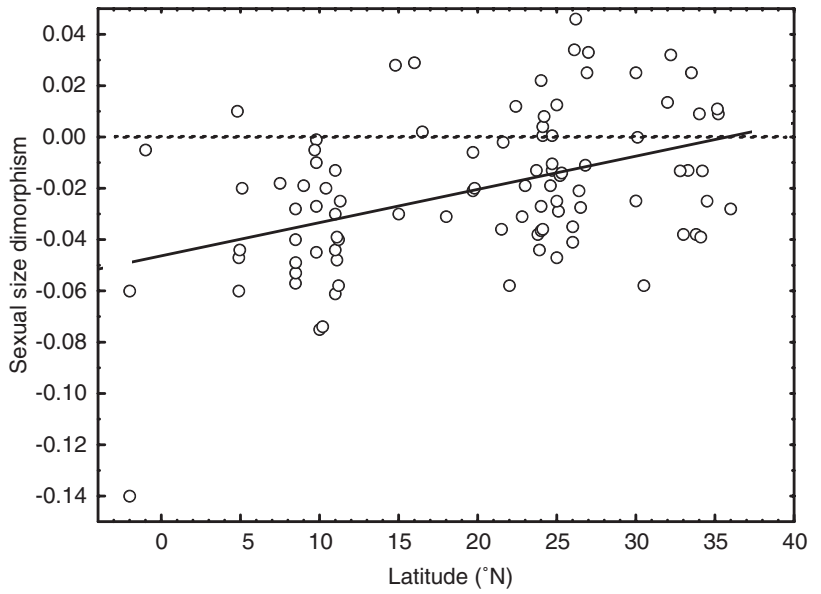

Fig. 4. Latitudinal variation in sexual size dimorphism of adults of the bruchid beetle Stator limbatus. Size units are arbitrary, above the dotted line females are larger, below it males are larger. Redrawn from Stillwell et al. (2007).

also be a consequence of stronger sex-specific selection on size associated with season length than selection as a consequence of temperature variation (Blanckenhorn et al., 2006). The only study to investigate both latitudinal size variation and SSD in detail concerns the bruchid Stator limbatus in South, Central and North America (Stillwell, Morse \& Fox, 2007). Adults of this species increase in size with latitude, and the slope of the relationship is steeper for females than it is for males. In consequence, SSD declines with increasing latitude (Fig. 4). The increase in size with latitude is correlated with increasing seed size, increasing seasonality, and declining moisture availability, suggesting that enhanced resistance to dry conditions and resource shortages, as well as resource availability are responsible for the cline. No correlation between size and several temperature variables was found, suggesting that the resistance hypothesis for size variation (i.e. better resistance to desiccation and/or resource shortages in larger individuals, see Cushman, Lawton \& Manly, 1993; Chown \& Gaston, 1999) is most significant in this species. Variation in SSD and latitude remained after the only significant environmental correlate of SSD was corrected for, suggesting either that varying sexual selection on males, or some other latitudinally varying difference in selection on males and females resulted in the latitudinal variation in SSD (Stillwell et al., 2007). Further work is required to understand the interaction between latitudinal size variation and size variation among the sexes, and particularly how it varies among species that show increases or declines in size with latitude.

\section{(b) Scaling}

Acknowledging that there is substantial feedback between body size, physiological traits and life history variables (Blanckenhorn, 2000b; Emlen \& Allen, 2004; Kozłowski et al., 2004; Mirth \& Riddiford, 2007; Shingleton et al., 2007), the influence of intraspecific body size variation is pervasive. 
Body size correlates with mortality from abiotic factors such as starvation, desiccation and low temperature (Lighton et al., 1994; Arnett \& Gotelli, 2003; Lehmann et al., 2006; Colinet, Vernon \& Hance, 2007), predation intensity (Nylin \& Gotthard, 1998), predator guild composition (Gaston et al., 1997), food particle size (Holter \& Scholtz, 2005), fecundity (Honík, 1993; Taylor, Anderson \& Peckarsky, 1998), mating and reproductive success (Stone, Loder \& Blackburn, 1995; Taylor et al., 1998), activity/foraging time (Stone, 1994; Cerdá \& Retana, 2000), the outcome of intraspecific competition (Heinrich \& Bartholomew, 1979), flight ability (Dudley, 2000a), and various aspects of morphology (e.g. Feener et al., 1988; Green, 1999; Shingleton et al., 2008; Eberhard, 2009). Where significant scaling relationships are documented they often show considerable variation, such that coefficients of determination are low, and are statistically weak owing to the small size range in many species, though morphological traits are typically an exception in this regard.

\section{(2) Interspecific}

Although data for insects have been employed in several classical studies of species-body size distributions (e.g. Hutchinson \& MacArthur, 1959; May, 1978), understanding of such distributions for insects has been severely constrained by biased sampling; larger species are much better represented than smaller ones. Temporal trends in the sizes of those species being formally taxonomically described were first documented quantitatively for insects (Gaston, 1991a; Gaston \& Blackburn, 1994; but see Cabrero-Sañudo \& Lobo, 2003). In several groups, as progressively more species came to be described, the mean body sizes of those that were known decreased through time and the skewness of the observed species-body size distributions increased (Blackburn \& Gaston, 1994a).

Nonetheless, reasonably well-documented species-body size distributions for major insect groups do not appear to differ markedly from those for other higher taxa. They are strongly right-skewed on untransformed axes, and typically approximately symmetric or still right-skewed when body size is logarithmically transformed, with departures from symmetry tending to become statistically more significant with increased numbers of species (e.g. Janzen, 1973; May, 1978; Morse et al., 1988; Basset \& Kitching, 1991; Hanski \& Cambefort, 1991; Dixon, Kindlmann \& Jarošik, 1995; Chown \& Steenkamp, 1996; Basset, 1997; Novotný \& Kindlmann, 1996; Novotný \& Wilson, 1997; Brändle et al., 2000; Hodkinson \& Casson, 2000; Krüger \& McGavin, 2000; Dixon \& Hemptinne, 2001; Espadaler \& Gómez, 2002; Ulrich, 2004; Agosta \& Janzen, 2005; Finlay et al., 2006). The vast majority of insect species are small, but the smallest species are not the most frequent. The greater numbers of small-bodied species do not, however, translate into simple negative relationships in insects between the species richness and body size of taxonomic groups (e.g. Katzourakis et al., 2001; Orme, Isaac \& Purvis, 2002; Finlay et al., 2006). Moreover, at a variety of scales, the speciesbody size distributions are similar, with peaks appearing at four distinct body sizes, representing, in order of size, the Scolytidae and Chironomidae; Curculionidae, Staphylinidae and Chrysomelidae; Noctuidae; and Nymphalidae (Finlay et al., 2006). The empirical data for the insects collected by Finlay et al. (2006) also fit the suggestion that small species are more widely dispersed, but do not suggest that the same applies to the largest species.

Mechanistic models, not always mutually exclusive, for the shape of species-body size distributions in general are based on $(i)$ the distributions of optimal sizes resulting from an interspecific trade-off between production and mortality (Kozłowski \& Weiner, 1997; Kindlmann, Dixon \& Dostalkova, 1999); (ii) patterns of speciation and extinction rates (Dial \& Marzluff, 1988; Maurer, Brown \& Rusler, 1992); (iii) the world being larger, or the environment or resources being more finely sub-divided, for smaller species (Hutchinson \& MacArthur, 1959; May, 1978; Shorrocks et al., 1991); and (iv) patterns of dispersal (Chown, 1997; Etienne \& Olff, 2004) (for further, more general discussion, see E.P. White et al., 2007). For insects, the importance of the size structure of resources has attracted the most explicit attention for herbivores (influenced by plant size structure; Dixon et al., 1995; Novotný \& Wilson, 1997), predators (influenced by prey size structure; Dixon \& Hemptinne, 2001) and parasites (influenced by host size; Johnson, Bush \& Clayton, 2005, see also Tompkins \& Clayton, 1999). In the last case, this relationship is known as Harrison's rule, but as with many such 'rules' (see discussion in Gaston, Blackburn \& Spicer, 1998; Millien et al., 2006; Gaston et al., 2008) it is not always supported by empirical data (Johnson et al., 2005). Nonetheless, it is difficult to escape the notion that, given the close relations between the sizes of many insects and those of the hosts and prey that they use, the size structure of the environment must have a profound influence on insect species-body size distributions (Morse et al., 1985). This is not at odds with species-body size distributions being shaped by intraspecific trade-offs between production and mortality, because resources can be considered as affecting the production function (itself the difference between assimilation and respiration; Kozłowski \& Gawelczyk, 2002).

Both at local and regional scales, the influence on speciesbody size distributions of transient or tourist species-those species present in an assemblage whose individuals obtain little if any of their nutrition directly or indirectly from resource bases that are present - has been a recurrent concern (e.g. Gaston et al., 1993; Chown \& Steenkamp, 1996). Likewise, at local scales, in insect assemblages the densities of species have typically been found at best to be weakly negatively related, and perhaps more frequently unrelated, to their body sizes (e.g. Morse et al., 1988; Gaston et al., 1993; Chown \& Steenkamp, 1996; Krüger \& McGavin, 2000). Evidence that this pattern generalises to greater spatial extents, let alone global scales, is scant (local studies alone may involve the identification of tens of thousands of individuals). However, those studies that have been conducted over greater extents provide little support for the notion that 
there is any simple relationship between abundance and body size in insects (e.g. Gaston \& Lawton, 1988; Gutiérrez \& Menéndez, 1997).

The implications of interspecific size variation for physiological and life-history traits have been explored in a wide variety of studies, with the number and scope thereof ever increasing. Examples include various aspects of biochemistry (Darveau et al., 2005a, b), stoichiometry (Fagan et al., 2002; Woods et al., 2004), metabolic rate (Chown et al., 2007), gas exchange characteristics (Lighton, 1991; C.R. White et al., 2007), wing loading and stroke frequency (Casey, May \& Morgan, 1985; Darveau et al., 2005b), post-flight cooling (Bartholomew \& Epting, 1975), aspects of water balance (Lehmann, Dickinson \& Staunton, 2000; AddoBediako, Chown \& Gaston, 2001), population abundance (e.g. Gaston et al., 1993), and rates of population increase (Gaston, 1988). In some cases, such as interspecific size variation in metabolic rate, development rate, and mortality, considerable feedback is likely, such that body size is as much a function of these variables as they are of body size at the intraspecific level (Kozłowski \& Gawelczyk, 2002), so determining optimum body size and eventually the interspecific relationship. How these interactions might play out in insects is only beginning to be explored (Chown \& Gaston, 1999; Blanckenhorn \& Demont, 2004; Chown et al., 2007). Much less seems to be known about other facets of body size scaling (or the lack thereof) at the interspecific level, such as that of polyunsaturated fatty acid content or membrane composition, tracheolar cross-sectional area, lipid content, critical oxygen tension, cuticle thickness, dispersal ability, geographic range size, and genetic variation, though some work has commenced (e.g. Greenlee, Nebeker \& Harrison, 1997; Kaiser et al., 2007).

\section{VARIATION IN SIZE THROUGH TIME}

\section{(1) Evolutionary trends}

Molecular evidence suggests that the insects arose from a common ancestor at the Silurian-Ordovician boundary approximately 434-421 million years before present (Myr BP) (Gaunt \& Miles, 2002; Grimaldi \& Engel, 2005). The fossil record for early insects and closely related groups is, however, poor. The earliest unrefuted evidence of insects in the fossil record is an archaeognathan from the Middle Devonian, and winged insects first appear in the fossil record in the Upper Carboniferous (c. 325 Myr BP; Shear \& Kukalová-Peck, 1990). Oxygen availability probably influenced the early diversification of arthropods, and the diversity of insects began to increase only following the end of a low oxygen period, known as Romer's Gap (see Ward et al., 2006), during the early Carboniferous (>325 Myr BP). Diversification was disrupted by notable, large extinction events, but continued to increase through to the present (Labandeira \& Sepkoski, 1993; Labandeira, Johnson \& Wilf, 2002; Wilf et al., 2006), with some periods showing important patterns, such as significant increases in herbivory during periods of high $\mathrm{CO}_{2}$ partial pressure (Currano et al., 2008).

\section{(a) Oxygen and gigantism}

Gigantism was taxonomically widespread in the late Palaeozoic, including amongst the Protodonata (wingspans may have ranged up to $710 \mathrm{~mm}$ ), Paleodictyoptera (wingspans of up to $560 \mathrm{~mm}$ ), Ephemeroptera (wingspans of up to $450 \mathrm{~mm}$ ), Diplura, and Thysanura (Shear \& KukalováPeck, 1990; Dudley, 1998; Wootton \& Kukalová-Peck, 2000). Amongst the dragonfly clade, wingspans varied by a 24 -fold range, compared with a sevenfold range amongst extant species (Wootton \& Kukalová-Peck, 2000). One vigorously championed mechanism for the occurrence of gigantism during this period (which also occurred in other invertebrate and lower vertebrate groups) was hyperoxia and hyperbaria in the Palaeozoic atmosphere, leading to a relaxation of constraints on tracheal diffusion and the power demands of flight musculature in winged species (Miller, 1966; Dudley, 1998, 2000a, b). Oxygen availability would also have been enhanced in the aquatic larval stages of many of the groups, though gigantism was apparently also common in terrestrial species. This oxygen pulse hypothesis is consistent with the subsequent loss of these forms with increasing hypoxia in the late Permian (Huey \& Ward, 2005), and the evolution of large size in at least one group (the mayfly family Hexagenitidae) during a second oxygen peak in the Cretaceous (Dudley, 2000b).

Although compelling, this hypothesis has not been well explored empirically or theoretically from the perspective of the changes in tracheolar density and gas exchange mechanics that might offset alterations in ambient oxygen availability (Dudley, 2000a, 2000b; Frazier, Woods \& Harrison, 2001; Greenlee \& Harrison, 2004; see also Schmitz \& Harrison, 2004; Harrison et al., 2006; Klok \& Harrison, 2009). Moreover, the evolution of large size and its subsequent decline might also involve interactions between oxygen availability, geographic range size and thermal tolerance. Reductions in geographic range size are thought to have been precipitated both by warming and by a decline in atmospheric oxygen levels (Huey \& Ward, 2005), and typically larger species require larger geographic ranges to avoid extinction. Aquatic stages may also have been compromised more than their terrestrial counterparts owing to differential changes in metabolic demand and oxygen flux (Huey \& Ward, 2005; Makarieva, Gorshkov \& $\mathrm{Li}, 2005)$, although flight metabolism in modern insects has a much lower critical $\mathrm{PO}_{2}$ than resting metabolism (Rascón \& Harrison, 2005). Hypoxic stress may also have lowered thermal tolerance (Pörtner, 2001) so reducing range sizes, especially if upper and lower thermal limits are decoupled as they appear to be in insects (Chown, 2001). However, the evidence for oxygen limitation of thermal tolerance in insects remains equivocal (Chown \& Terblanche, 2007). Perhaps the most promising work in this area suggests that limitations to size are set by steeper scaling of the cross-sectional area of the tracheae in the legs (mass ${ }^{1.02}$ ) than of the cross-sectional 


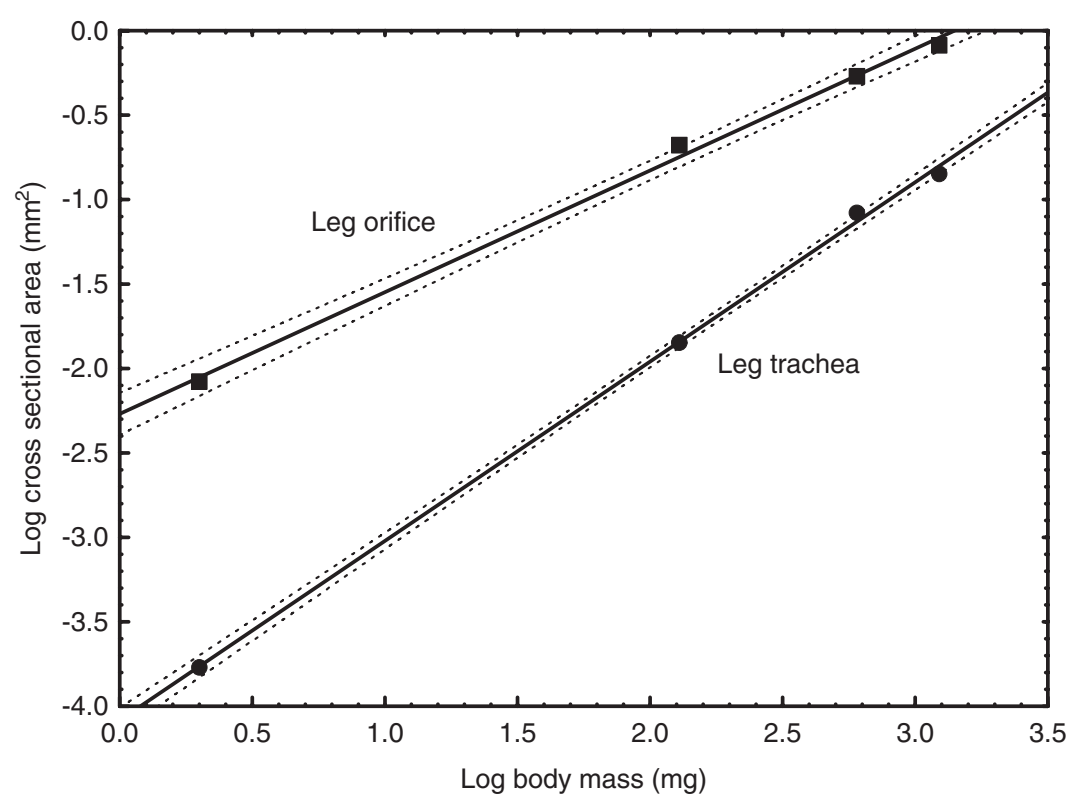

Fig. 5. Scaling of tracheal cross-sectional area (isometry-mass ${ }^{1.02}$ ), and leg orifice (i.e. the opening from the body to the leg through which tracheae and haemolymph pass) cross-sectional area (shallow allometry-mass ${ }^{0.77}$ ) in four species of tenebrionid beetles. The interaction of the two relationships could set the upper limit to size. Redrawn from Kaiser et al. (2007).

area of the leg opening to the main body cavity through which the tracheae and haemolymph must pass (the crosssectional area of this opening (or orifice) scales as mass ${ }^{0.77}$ ) (Kaiser et al., 2007) (Fig. 5). These scaling differences mean that space available for tracheae in the legs may limit the size of an insect, and such limitations may well apply to other constrictions of the exoskeleton. Under experimental, hyperoxic conditions, insects reduce the dimensions of their tracheae, which suggests that during such conditions in the past, the constraints on large size may have been reduced substantially, so leading to gigantism (Kaiser et al., 2007).

Alternative hypotheses include the evolution of large size as a defensive adaptation of Palaeozoic arthropods in response to predation by vertebrates, of which the majority at the time were insectivorous or predators on other vertebrates (Shear \& Kukalová-Peck, 1990). Changes in size, particularly later reductions, might also have been mediated by changing mortality risks that must have been encountered by juvenile stages. In this context it is notable that the largest recent insects (extant or recently extinct) either typically spend the bulk of their lives as concealed feeders (e.g. beetle species in the Cerambycidae, Scarabaeidae, Dynastinae) or are restricted to oceanic islands where predation pressure may be lower (e.g. St Helena giant earwig Labidura herculeana, New Zealand giant weta Deinacrida spp.). In addition, the late Permian not only saw the loss of giant insects, but a mass extinction of insect diversity (Labandeira \& Sepkoski, 1993). Assuming that before this decline most insect species were nonetheless small-bodied relative to the absolute giants, and that the largest bodied species were still comparatively uncommon, then even random losses of species with respect to body size would almost certainly have seen the loss of the more giant forms. Which of these mechanisms is likely to have had the predominant role in promoting gigantism, and its subsequent disappearance, is difficult to determine, but the question deserves further exploration in the context of the factors determining final body size in insects.

\section{(b) Cope's rule}

A general empirical trend for selection acting on individual organisms predominantly to favour larger body size has been argued to translate, if unopposed, into a macroevolutionary trend toward increased size (Kingsolver \& Pfennig, 2004). Such a pattern is known as Cope's rule. Clearly the existence of many large-bodied forms early in the evolution of the insects means that the rule has not been obeyed over the entire duration of the insects, either for the group as a whole, or for several major clades.

However, the picture may appear rather different if one focuses on the period post the Permian mass extinction. Endopterygote insects predominate in recent insect faunas, particularly those in the orders Coleoptera, Hymenoptera, Diptera and Lepidoptera (Gaston, 1991b). Although the ancestors of at least some of these groups were present in the Permian, they all underwent dramatic and continued diversification after the mass extinction event, and have continued to do so through to the present (Labandeira \& Sepkoski, 1993; Gaunt \& Miles, 2002). In all four orders it seems likely that the largest recent species are amongst, if not actually, the largest that have existed (Coleoptera: largest recent species detailed earlier; Hymenoptera: wasps in the genus Pepsis can reach a wingspan of $100 \mathrm{~mm}$; Diptera: largest species is Gauromydas heros with a body length of about $60 \mathrm{~mm}$; Lepidoptera: largest wingspan is that of the white 
witch moth Thysania agrippina at $280 \mathrm{~mm}$ or more; Gauld \& Bolton, 1988; Kons, 1998).

Within particular clades, phyletic size increase has been explored for only a single family, the carabids. Of the 34 groups examined, seven showed significantly positive correlations between body size and cladogram position (indicating phyletic size increase), two showed significantly negative relationships, and in the remainder there was no relationship between size and cladogram position (Liebherr, 1988). Although a macroevolutionary trend towards large size is thus uncommon in the family, it is not randomly distributed amongst taxa. Typically, phyletic size increase is associated with brachyptery, and with groups inhabiting stable environments, although the mechanisms responsible for this trend have not been fully explored.

\section{(c) Evolutionary rates}

Both the standing diversity and the history of the body size of insects plainly reveal how rapidly body size changes can evolve and how developmentally plastic they can be. This has also been demonstrated both indirectly and directly by a variety of laboratory selection experiments. In the former case, David et al. (1997) demonstrated that laboratory-reared Drosophila melanogaster show both a reduction in size and change in kurtosis of the size frequency distribution relative to their wild counterparts. In the latter, numerous experiments have shown that size changes can be effected rapidly within generations depending on external conditions such as food availability or oxygen tension (e.g. Emlen \& Nijhout, 2000; Frazier et al., 2001), and that selection can effect rapid size changes between generations (e.g. Gibbs, Chippindale \& Rose, 1997).

In the field, rapid evolution of body size has been shown in Drosophila subobscura (Huey et al., 2000). This species is native to the Old World, where it displays a positive cline in wing length with latitude. It was, however, introduced to North and South America, where it spread rapidly, evolving a cline in body size that largely converged on that observed in the Old World, although the way in which the variation in size was achieved is different. Thus, in North America, an increase in wing length with latitude has been achieved largely through changes in the relative length of the distal portion of vein IV, whereas in Europe lengthening is a consequence of a relative increase in length of the basal portion of this vein. Likewise, the threshold for horn development in the beetle Onthophagus taurus evolved rapidly, in opposite directions, in populations introduced to Western Australia and eastern North America from the Mediterranean region (Moczek \& Nijhout, 2003).

\section{(2) Ecological trends}

\section{(a) Intraspecific level}

Seasonal variation in body size, in species where there is no period of diapause or quiescence, has been described inter alia for stoneflies (Haro, Edley \& Wiley, 1994), blackflies (Colbo \& Porter, 1979; Baba, 1992), Drosophila spp. (Tantawy,

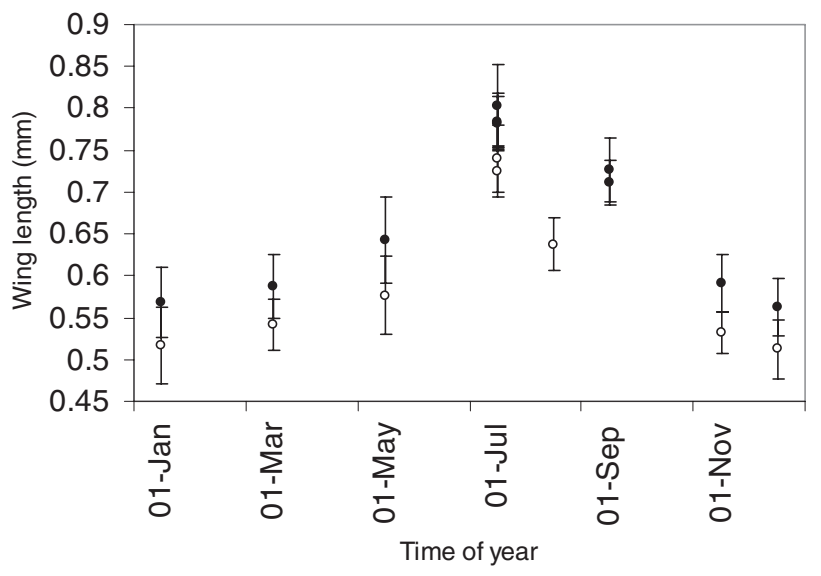

Fig. 6. Seasonal variation in means \pm S.E.M. wing length ( $\mathrm{mm})$ of female (filled symbols) and male (open symbols) Simulium chutteri (Diptera, Simuliidae) collected over the course of a single year along the Orange River in South Africa (data from Myburgh, 2001). July is the lowest temperature period of the year.

1964; Kari \& Huey, 2000), mosquitoes (Yuval et al., 1993), tsetse flies (Rogers \& Randolph, 1991), beetles (Ernsting \& Isaaks, 1997), a parasitoid wasp (Sequiera \& Mackauer, 1993), a bee (Alcock, Simmons \& Beveridge, 2005), and butterflies (Rodrigues \& Moreira, 2004) (see Fig. 6). In the majority of these cases developmental temperature has the most significant influence on body size, such that size tends to be largest at the lowest temperatures. Kari \& Huey (2000) suggested that in D. subobscura resource availability and/or stressful abiotic conditions probably also influence the seasonal pattern (see also Baba, 1992). This is in keeping with many investigations of resource competition and the effects of stress on insects (e.g. Hirschberger, 1999; Vessby, 2001; Warren et al., 2006), and with mechanistic investigations of the response of insects to resource deprivation (e.g. Blanckenhorn, 1999; Mirth \& Riddiford, 2007). Such developmental phenotypic plasticity is not uncommon in insects (for recent review and discussion of phenotypic plasticity see DeWitt \& Scheiner, 2004; Ghalambor et al., 2007; Angilletta, 2009).

Interannual variation in size has also been investigated in several species (Alcock, 1984; Evans, 2000; Smith et al., 2000). Typically, this variation is not substantial (Fig. 7), and the likely causes have not been systematically explored. The ultimate mechanisms may well be similar to those responsible for spatial variation in size (see below), such as differences in selection intensity and direction (e.g. Kingsolver et al., 2007). Clearly, size changes must be mediated by a variety of proximate physiological mechanisms which determine final adult size (see Section II.2 above). For example, in Manduca sexta an evolutionary increase in body size after 220 generations in the laboratory was a consequence of elevated growth rate, increased critical weight, and a prolonged ICG, or the interval between the critical weight 
A

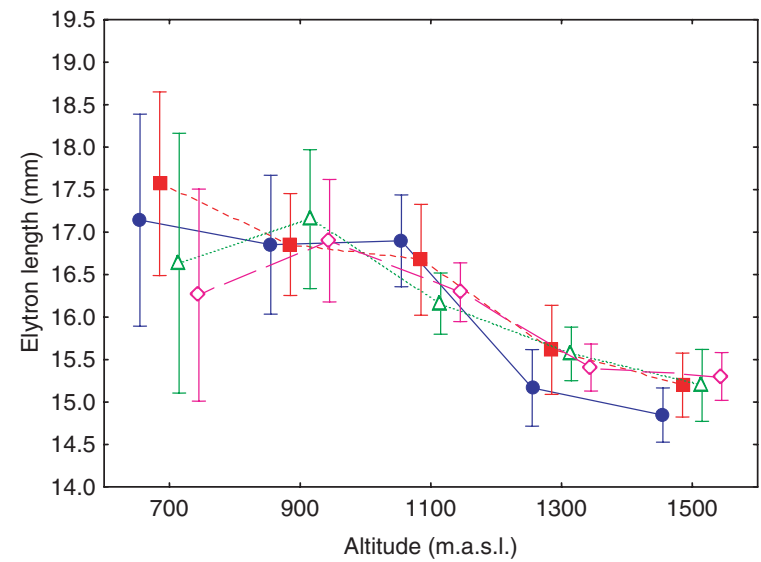

B

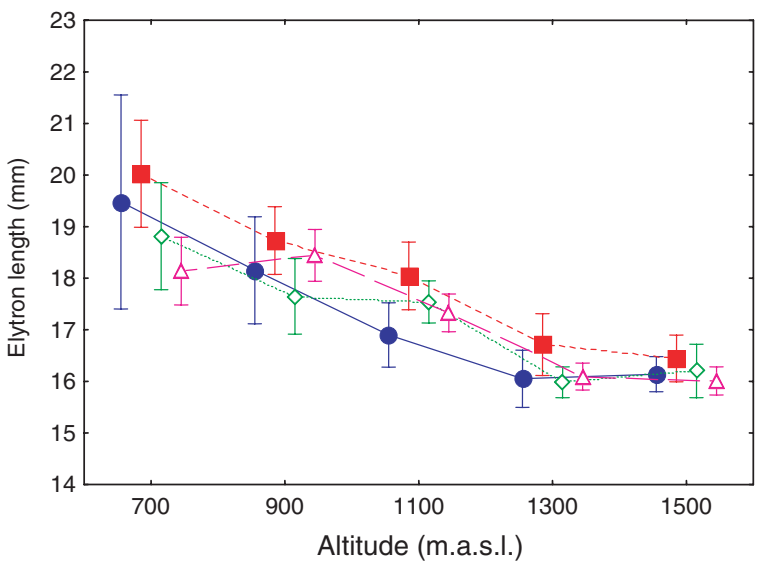

Fig. 7. Elytron length variation (mean $\pm 95 \%$ C.I.) in (A) males and (B) females of the carabid beetle Thermophilum decemguttatum along the western slopes of the Cederberg in South Africa. Four years are shown (solid line and filled circles-October 2002; broken line and solid squares-October 2003; dashed line and open triangles-October 2004; broken line and open diamonds-October 2005). Redrawn from Gouws (2007).

and prothoracicotropic hormone secretion (D'Amico et al., 2001).

\section{(b) Interspecific and assemblage levels}

The average body sizes of species in insect assemblages tend to decline with ecological succession, both at individual sites through time as succession progresses and across sites of different successional status (e.g. Steffan-Dewenter \& Tscharntke, 1997; Siemann, Haarstad \& Tilman, 1999; Braun, Jones \& Perner, 2004). This is despite the species richness of different groups increasing, decreasing, and remaining approximately stable. A similar trend in body size tends to occur along gradients of increasing disturbance (e.g. Blake et al., 1994; Grandchamp, Niemelä \& Kotze, 2000; Braun et al., 2004). Both patterns probably result from changes in the environmental constraints on body size, particularly those associated with vegetational complexity

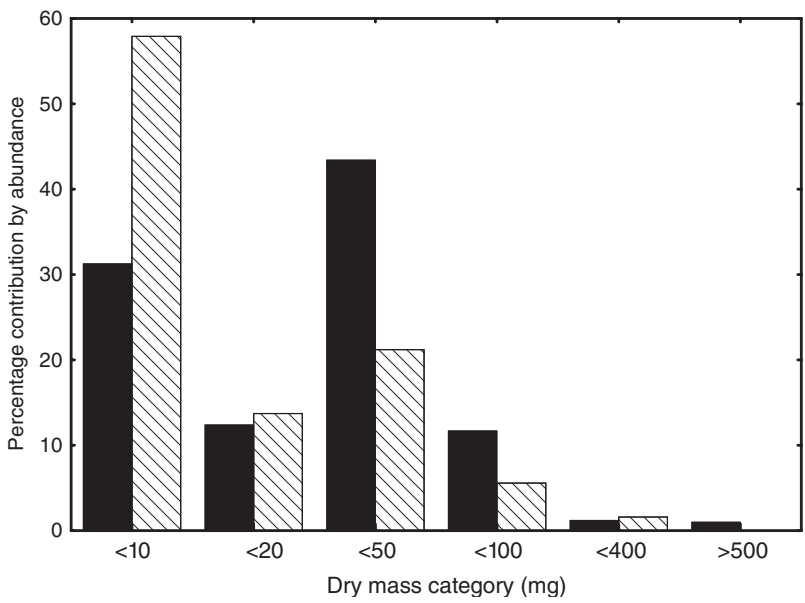

Fig. 8. Body size differences in the dung beetle assemblages occupying a dry savanna (filled bars) and a nearby area heavily invaded by Prosopis glandulosa (Fabaceae) (hatched bars) in the Northern Cape of South Africa. Note the predominance of small-bodied species in the invaded site. Data from Steenkamp \& Chown (1996).

and stability. However, dramatic changes in vegetation structure, such as those associated with the transformation of landscapes by invasive alien species, can also have substantial impacts on assemblage body size distributions. Typically, large species are lost from the assemblage, probably as a consequence of flight impairment by dense vegetation and a change in resource availability (Steenkamp \& Chown, 1996; Coetzee, van Rensburg \& Robertson, 2007) (Fig. 8). By contrast, the relationship between habitat fragmentation effects and size is often weak or not significant. For example, Didham et al. (1998) found no variation in mean size among beetle species that responded differently to forest fragmentation in Brazil. Idiosyncratic responses of differentsized beetles to habitat alteration were found in the Atherton Tablelands of Australia (Grimbacher, Catterall \& Kitching, 2008). In a forest fragmentation experiment, involving 80100 yr old Eucalyptus regrowth forest, Davies, Margules \& Lawrence (2000) similarly found no relationship between response to fragmentation and body size in ground-dwelling beetles. Among the reasons for the variation in responses are the likelihood of large size benefiting desiccation tolerant species in relatively dry, small forest fragments on the one hand, but small body size reducing extinction risk on the other (Grimbacher et al., 2008). Nonetheless, it should be recognized that the relationship between size and extinction risk is indirect and complicated by size-related variation in abundance, population growth rate and population fluctuations (Davies et al., 2000).

Two analyses have also demonstrated that the likelihood of island invasion by insects might well be size dependent, thus having a significant influence on size distributions. A negative relationship between the probability of establishment of an insect invader accidentally or intentionally introduced to the British Isles and its body size has been reported (Lawton \& Brown, 1986), and a similar pattern was found within 
higher taxa for the insects of sub-Antarctic Marion Island (Gaston, Chown \& Mercer, 2001). Convincing explanations for this pattern are yet to be found, but may have to do with relationships between body size, abundance, and probability of detection by humans, who serve as vectors via transport of the species by vehicle.

\section{VARIATION IN SIZE THROUGH SPACE}

\section{(1) Intraspecific patterns}

The two primary patterns of spatial variation in body size are those concerned with latitudinal and altitudinal gradients. Recent reviews have documented patterns for both gradients (Chown \& Gaston, 1999; Blanckenhorn \& Demont, 2004; Dillon, Frazier \& Dudley, 2006). In many species, body size, usually measured as characteristic linear dimensions, increases with latitude (Table 1). Altitudinal size variation has been investigated in a smaller number of species (Table 2), and size increases have been documented in several of these (Dillon et al., 2006). Often, the patterns are not simply a consequence of plasticity because size variation is retained when populations are maintained under common garden conditions (James, Azevedo \& Partridge, 1995; Arnett \& Gotelli, 1999b; Huey et al., 2000; Loeschcke, Bundgaard \& Barker, 2000; Blanckenhorn et al., 2006; Stillwell et al., 2007), and the genetic basis of spatial size variation is now starting to be explored (Weeks, McKechnie \& Hoffmann, 2002).

Size increases with latitude and altitude are often referred to as Bergmann's rule (Chown \& Gaston, 1999; Blanckenhorn \& Demont, 2004), although the original application of this term by Bergmann was to interspecific, rather than intraspecific patterns. Despite the proposal that the intraspecific version be termed James' rule, to distinguish it from the more complex interspecific situation (see below) (Blackburn, Gaston \& Loder, 1999), this usage has not been widely adopted. Rather, positive relationships between size and latitude are still known as Bergmann clines and the opposite as converse Bergmann clines (Blanckenhorn et al., 2006).

Converse Bergmann clines (i.e. size declines with latitude) have been documented in several species (Table 1). In some of them, the declines are not constant, but take the form of a saw-tooth cline, such that increasing season length leads to increasing body size until two generations can be incorporated within a season, at which point the body size declines precipitously (Roff, 1980; Masaki, 1996). Altitudinal declines in size have also been documented (Table 2). Again, these patterns have been shown to have a strong genetic basis.

The proximate and ultimate explanations for these opposing size clines is the subject of a large, contentious and growing literature, and we consider this in more detail in Section VII. However, despite the complexity of this debate, by definition it only pertains to a relatively small number of species: those with geographic ranges that typically cover tens of degrees of latitude or hundreds (but often thousands) of metres of altitude (Gaston et al., 2008). These are the 'common' species in macroecology, which constitute a small proportion of any given higher taxon. Range size frequency distributions are usually strongly right-skewed, such that the majority of species are rare (Gaston \& Blackburn, 2000), and this is true of insects too (Gaston \& Chown, 1999). Therefore, questions regarding latitudinal and altitudinal patterns in size variation only apply to a small number of species, and discussions of the significance of, and relationships between, various ecogeographic rules (e.g. Blanckenhorn et al., 2006; Gaston et al., 2008) at the intraspecific level especially must necessarily concern a small proportion of insect diversity.

\section{(2) Interspecific and assemblage patterns}

The entomological literature also has its share of investigations of multispecies body size clines. These take two forms, distinguished by Gaston et al. (2008) as interspecific and assemblage analyses. Interspecific analyses treat different species as separate data points, typically plotting average size against the position (usually the midpoint) of the range of that species on a latitudinal or altitudinal gradient. In assemblage analyses the data points are different areas (sites), and typically the average size of the species occurring in an area is plotted against the position of that area on a latitudinal or altitudinal gradient. Whilst related, in as much as they can be derived from the same sites by species matrix, interspecific and assemblage approaches document rather different things. The former captures how between-species variation in body size changes with the distribution of those species across the landscape, and the latter captures how variation in the body size composition of species assemblages changes across the landscape. For assemblage analyses, increases (Hawkins \& Lawton, 1995), declines (Barlow, 1994) or no simple change (Hawkins, 1995) in size with latitude have been documented, whilst for interspecific analyses, increases (Moreteau et al., 2003) and declines (Diniz-Filho \& Fowler, 1998) with latitude have been found.

Several adaptive arguments have been proposed (and debated) for such spatial change in average body sizes, with the most common hypothesis being that it is driven by enhanced tolerance of starvation or desiccation (Cushman et al., 1993; Kaspari \& Vargo, 1995; Blackburn et al., 1999; Chown \& Gaston, 1999). However, interspecific body size clines, especially if expressed as means for a given geographic location, are much more difficult to interpret than intraspecific geographic size variation. Interspecific clinal size variation is a consequence of geographic changes in the location and shape of the interspecific species-body size distribution. Thus, the form of interspecific or assemblage size clines depends on beta diversity (the spatial pattern of species gains and losses), as well as the form of the intraspecific size clines of the species that are retained across more than two sites. Therefore, clines could take virtually any form. The latter has been demonstrated several times, as has the influence of spatial turnover of higher taxa on the form of the interspecific or assemblage size cline (Hawkins \& Lawton, 1995; Chown \& Klok, 2003; Brehm \& Fiedler, 2004). 
Table 1. The direction of latitudinal size variation in insects at the intraspecific, interspecific and assemblage levels. $*=$ no size range data could be extracted. Negative $=$ decline in size with increasing latitude.

\begin{tabular}{|c|c|c|c|c|c|}
\hline Taxon & Higher taxon & Direction & Dependent variable & Size range & Source \\
\hline \multicolumn{6}{|l|}{ Intraspecific } \\
\hline Myrmica rubra & Hymenoptera & Curvilinear & Mass & $3.0-3.4 \mathrm{mg}$ & Elmes et al. (1999) \\
\hline Enallagma cyathiagerun & Odonata & Curvilinear & Forewing length & $19.7-24.1 \mathrm{~mm}$ & Johansson (2003) \\
\hline Carabus nemoralis & Coleoptera & Negative & Elytron length & $14.5 \mathrm{~mm}$ & Blanckenhorn \& Demont (2004) \\
\hline Dicaelus purpuratus & Coleoptera & Negative & Length & $20-28 \mathrm{~mm}$ & $\operatorname{Park}(1949)$ \\
\hline Glossina palpalis & Diptera & Negative & Wing cell size & $1.3-1.7 \mathrm{~mm}$ & Rogers \& Randolph (1991) \\
\hline Aquarius remigis & Hemiptera & Negative & Total length & $12-16 \mathrm{~mm}$ & Brennan \& Fairbairn (1995) \\
\hline Aphantopus hyperantus & Lepidoptera & Negative & Wing length & $16.5-24 \mathrm{~mm}$ & Nylin \& Svard (1991) \\
\hline Coenonympha arcania & Lepidoptera & Negative & Wing length & $15-20 \mathrm{~mm}$ & Nylin \& Svard (1991) \\
\hline Coenonympha hero & Lepidoptera & Negative & Wing length & $13.5-15.5 \mathrm{~mm}$ & Nylin \& Svard (1991) \\
\hline Coenonympha pamphilus & Lepidoptera & Negative & Wing length & $12.5-17.5 \mathrm{~mm}$ & Nylin \& Svard (1991) \\
\hline Coenonympha tullia & Lepidoptera & Negative & Wing length & $15-22 \mathrm{~mm}$ & Nylin \& Svard (1991) \\
\hline Erebia ligea & Lepidoptera & Negative & Wing length & $18-25 \mathrm{~mm}$ & Nylin \& Svard (1991) \\
\hline Heodes virgaureae & Lepidoptera & Negative & Wing length & $13-17 \mathrm{~mm}$ & Nylin \& Svard (1991) \\
\hline Lasiommata maera & Lepidoptera & Negative & Wing length & $22-28 \mathrm{~mm}$ & Nylin \& Svard (1991) \\
\hline Lymantria dispar & Lepidoptera & Negative & Wing length & $24-30 \mathrm{~mm}$ & Blanckenhorn (2006) \\
\hline Papilio canadensis & Lepidoptera & Negative & Mass & $600-900 \mathrm{mg}$ & Ayres \& Scriber (1994) \\
\hline Pararge aegeria & Lepidoptera & Negative & Wing length & $19-25 \mathrm{~mm}$ & Nylin \& Svard (1991) \\
\hline Acheta veletis & Orthoptera & Negative & Body length & $14-26 \mathrm{~mm}$ & Alexander \& Bigelow (1960) \\
\hline Caledia captiva & Orthoptera & Negative & Pronotum length & $3.8-5.2 \mathrm{~mm}$ & Groeters \& Shaw (1996) \\
\hline Chorthippus brunneus & Orthoptera & Negative & Mass & $4.5-6.0 \mathrm{mg}$ & Telfer \& Hassall (1999) \\
\hline Teleogryllus emma & Orthoptera & Negative & Head width & $5.2-7.3 \mathrm{~mm}$ & Masaki (1967) \\
\hline Hipparchia semele & Lepidoptera & None & Wing length & $21.5-30 \mathrm{~mm}$ & Nylin \& Svard (1991) \\
\hline Lasiommata megera & Lepidoptera & None & Wing length & $18.5-24.5 \mathrm{~mm}$ & Nylin \& Svard (1991) \\
\hline Lasiommata petropolitana & Lepidoptera & None & Wing length & $1-22 \mathrm{~mm}$ & Nylin \& Svard (1991) \\
\hline Lyacaena helle & Lepidoptera & None & Wing length & $12-15 \mathrm{~mm}$ & Nylin \& Svard (1991) \\
\hline Lyacaena phlaeas & Lepidoptera & None & Wing length & $11-17 \mathrm{~mm}$ & Nylin \& Svard (1991) \\
\hline Maniola jurtina & Lepidoptera & None & Wing length & $18-26 \mathrm{~mm}$ & Nylin \& Svard (1991) \\
\hline Palaeocrysophanus hippothoe & Lepidoptera & None & Wing length & $14-17 \mathrm{~mm}$ & Nylin \& Svard (1991) \\
\hline Phyllotreta striolata & Coleoptera & Positive & Elytron length & $2.0 \mathrm{~mm}$ & Blanckenhorn \& Demont (2004) \\
\hline Stator limbatus & Coleoptera & Positive & Elytron length/width & $*$ & Stillwell et al. (2007) \\
\hline Drosophila aldrichi & Diptera & Positive & Thorax length & $*$ & Loeschcke et al. (2000) \\
\hline Drosophila buzzatii & Diptera & Positive & Thorax length & $*$ & Loeschcke et al. (2000) \\
\hline Drosophila kikkawi & Diptera & Positive & Wing length & $9.7 \mathrm{~mm}$ & Karan et al. (1998) \\
\hline Drosophila melanogaster & Diptera & Positive & Wing area & $1.4-2.2 \mathrm{~mm}^{2}$ & James et al. (1997) \\
\hline Drosophila melanogaster & Diptera & Positive & Wing length & $1.37-1.61 \mathrm{~mm}$ & Imasheva et al. (1994) \\
\hline Drosophila melanogaster & Diptera & Positive & Mass & $0.9-1.1 \mathrm{mg}$ & David \& Bocquet (1975) \\
\hline Drosophila melanogaster & Diptera & Positive & Thorax length & $1.1-1.6 \mathrm{~mm}$ & Hoffmann et al. (2001) \\
\hline Drosophila melanogaster & Diptera & Positive & Wing: thorax size ratio & $1.35-1.55$ & Azevedo et al. (1998) \\
\hline Drosophila melanogaster & Diptera & Positive & Thorax length & $0.92-1.10 \mathrm{~mm}$ & James et al. (1995) \\
\hline Drosophila serrata & Diptera & Positive & Wing length & $0.9-1.4 \mathrm{~mm}$ & Hallas et al. (2002) \\
\hline Drosophila simulans & Diptera & Positive & Mass & $*$ & David \& Bocquet (1975) \\
\hline Drosophila subobscura & Diptera & Positive & Wing length & $2.22-2.61 \mathrm{~mm}$ & Calboli et al. (2003) \\
\hline Drosophila subobscura & Diptera & Positive & Wing length & $2.3-3.2 \mathrm{~mm}$ & Gilchrist \& Huey (2004) \\
\hline Drosophila subobscura & Diptera & Positive & Wing length & $0.8-0.95 \mathrm{~mm}$ & Huey et al. (2000) \\
\hline Drosophila subobscura & Diptera & Positive & Wing width & $0.89-1.5 \mathrm{~mm}$ & Gilchrist et al. (2004) \\
\hline Musca domestica & Diptera & Positive & Wing length & $2-6 \mathrm{~mm}$ & Bryant (1977) \\
\hline Scathophaga stercoraria & Diptera & Positive & Hind tibia length & $2.7-3.7 \mathrm{~mm}$ & Blanckenhorn \& Demont (2004) \\
\hline Zaprionus indianus & Diptera & Positive & Mass & $0.13-0.12 \mathrm{mg}$ & Karan et al. $(2000)$ \\
\hline Pemphigus populitransversus & Homoptera & Positive & Wing length & $2 \mathrm{~mm}$ & Blanckenhorn \& Demont (2004) \\
\hline Apis mellifera & Hymenoptera & Positive & Forewing length & $9.15 \mathrm{~mm}$ & Daly et al. (1991) \\
\hline Apis mellifera & Hymenoptera & Positive & Wing length & $8-10 \mathrm{~mm}$ & Alpatov (1929) \\
\hline Leptothorax acervorum & Hymenoptera & Positive & Thorax length & $1.05-1.15 \mathrm{~mm}$ & Heinze et al. (1998) \\
\hline Leptothorax acervorum & Hymenoptera & Positive & Thorax length & $0.98-1.18 \mathrm{~mm}$ & Heinze et al. (2003) \\
\hline Nomia melanderi & Hymenoptera & Positive & Mass & $130-180 \mathrm{mg}$ & Rust (2006) \\
\hline Myrmeleon immaculatus & Neuroptera & Positive & Body mass & $0.019-0.1 \mathrm{~g}$ & Arnett \& Gotelli (2003) \\
\hline Myrmeleon immaculatus & Neuroptera & Positive & Head width & $1.19-1.25 \mathrm{~mm}$ & Arnett \& Gotelli (1999a) \\
\hline
\end{tabular}


Table 1. (Cont.)

\begin{tabular}{|c|c|c|c|c|c|}
\hline Taxon & Higher taxon & Direction & Dependent variable & Size range & Source \\
\hline Allonemobius fasciatus & Orthoptera & Sawtooth & Femur length & $5.6-6.8 \mathrm{~mm}$ & Mousseau \& Roff(1989) \\
\hline Pteronemobius taprobanensis & Orthoptera & Sawtooth & Head width & $1.7-1.95 \mathrm{~mm}$ & Masaki (1978) \\
\hline \multicolumn{6}{|l|}{ Interspecific } \\
\hline Butterflies & Lepidoptera & Negative & Forewing length & $17.5-21 \mathrm{~mm}$ & Hawkins \& Lawton (1995) \\
\hline Butterflies & Lepidoptera & Negative & Forewing length & $19-23 \mathrm{~mm}$ & Hawkins \& Lawton (1995) \\
\hline Termites & Isoptera & None & Colony size & $*$ & Porter \& Hawkins (2001) \\
\hline Butterflies & Lepidoptera & None & Forewing length & $18.5-19 \mathrm{~mm}$ & Hawkins \& Lawton (1995) \\
\hline Ants & Hymenoptera & Positive & Body length & $4.5-6.5 \mathrm{~mm}$ & Cushman et al. (1993) \\
\hline Butterflies & Lepidoptera & Positive & Forewing length & $18-21 \mathrm{~mm}$ & Hawkins \& Lawton (1995) \\
\hline Bees & Hymenoptera & Variable & Body length & $7-15 \mathrm{~mm}$ & Hawkins (1995) \\
\hline \multicolumn{6}{|l|}{ Assemblage } \\
\hline Butterflies & Lepidoptera & Curvilinear & Forewing length & $17-23 \mathrm{~mm}$ & Hawkins \& Lawton (1995) \\
\hline Butterflies & Lepidoptera & Negative & Forewing length & $17-23 \mathrm{~mm}$ & Hawkins \& Lawton (1995) \\
\hline Butterflies & Lepidoptera & Negative & Wingspan & $36-56 \mathrm{~mm}$ & Barlow (1994) \\
\hline Butterflies & Lepidoptera & None & Forewing length & $17-23 \mathrm{~mm}$ & Hawkins \& Lawton (1995) \\
\hline Ants & Hymenoptera & Positive & Colony size & $*$ & Kaspari \& Vargo (1995) \\
\hline Ants & Hymenoptera & Positive & Body length & $4.5-6.5 \mathrm{~mm}$ & Cushman et al. (1993) \\
\hline Butterflies & Lepidoptera & Positive & Forewing length & $17-23 \mathrm{~mm}$ & Hawkins \& Lawton (1995) \\
\hline Bees & Hymenoptera & Variable & Body length & $7-15 \mathrm{~mm}$ & Hawkins (1995) \\
\hline
\end{tabular}

What has perhaps not been as clearly recognized is that adaptive explanations at the assemblage level make the implicit assumption either that the average body size of the assemblage is being optimised, or that a certain size is optimal for a given reason, and will be achieved irrespective of species-specific life-history variation. Both scenarios seem unlikely, except under the condition that there is an optimal body size for a given higher taxon (e.g. Brown, Marquet \& Taper, 1993), which seems entirely unlikely (Chown \& Gaston, 1997; Kozłowski \& Gawelczyk, 2002).

\section{MODELS FOR ADULT GLINAL SIZE VARIATION}

Many models exist which examine the relationship between age and size at maturity and the associated trade-offs which limit the scope of variation seen in natural populations. Several of these, as well as a variety of other, sometimes less mathematically formal approaches, have been used in attempts to explain the existence of clines in body size. Much of the focus has been on the increase in size with latitude or altitude, which is sometimes also known as the temperature-size rule, owing to the tendency for organisms to develop to larger sizes when reared at lower temperatures (Atkinson, 1994), and which has also been called a puzzle for life historians (Berrigan \& Charnov, 1994). The underlying mechanistic explanations for size clines continue to be contentious, with several authors expressing the view that the reasons for 'Bergmann clines' remain unclear (Angilletta \& Dunham, 2003; Blanckenhorn \& Demont, 2004; Blanckenhorn et al., 2006; Kingsolver et al., 2007).

Before discussing the various explanations for changing adult size with changing altitude and latitude (and season), it is important to recognize that few of these explicitly make a formal connection to investigations of the proximate physiological mechanisms for size variation discussed in Section II. Often this connection is implied, but explicit discussion of variation in critical weight, rate of growth prior to and after the critical weight, and duration of the ICG is uncommon. Where such discussion does take place, it is usually driven by those investigating the proximate physiological mechanisms as a means to explain spatial patterns in size variation (see e.g. Davidowitz \& Nijhout, 2004; Nijhout et al., 2006). In consequence, here, the various explanations proposed for size variation will be reviewed as they have been presented by their proponents. Thereafter, integration with mechanistic physiological explanations will be provided in the context of a general model for size variation.

Essentially, the explanations for size clines can be thought of as those that are explicitly adaptive and those that involve some form of biophysical constraint that may or may not be the subject of selection. The biophysical constraints generally concern the temperature sensitivity of different aspects of organismal development, such as growth versus differentiation (e.g. van der Have \& de Jong, 1996), and have the closest connections to the proximate physiological mechanisms determining size. The most prominent of the constraint-based explanations for positive size clines (or Bergmann's clines) are the differential sensitivity of growth and development (van der Have \& de Jong, 1996), and to some extent the difference in the temperature thresholds of growth and development (Walters \& Hassall, 2006; see also de Jong \& van der Have, 2008). Following re-assessment of the former, Walters \& Hassall (2006) concluded that the slope of the rate-temperature curve is of much less significance than the relative position of its threshold. However, they also argued that selection for increases or declines in body size operates through variation in the relative positions of the 
Table 2. The direction of altitudinal size variation in insects at the intraspecific, interspecific and assemblage levels. Negative $=$ decline in size with increasing altitude.

\begin{tabular}{|c|c|c|c|c|c|}
\hline Taxon & Higher taxon & Direction & Dependent variable & Size range & Source \\
\hline \multicolumn{6}{|l|}{ Intraspecific } \\
\hline Adesmia metallica & Coleoptera & Negative & Elytron length & $9-15 \mathrm{~mm}$ & Krasnov et al. (1996) \\
\hline Bothrometopus gracilipes & Coleoptera & Negative & Body length & $4.4-4.9 \mathrm{~mm}$ & Chown \& Klok (2003) \\
\hline Canonopsis sericeus & Coleoptera & Negative & Body length & $10.0-10.7 \mathrm{~mm}$ & Chown \& Klok (2003) \\
\hline Ectemnorhinus viridis & Coleoptera & Negative & Body length & $4.9-6.6 \mathrm{~mm}$ & Chown \& Klok (2003) \\
\hline Erodius edomitus & Coleoptera & Negative & Elytron length & $8-12 \mathrm{~mm}$ & Krasnov et al. (1996) \\
\hline Zophosis complanata & Coleoptera & Negative & Elytron length & $6.5-12 \mathrm{~mm}$ & Krasnov et al. (1996) \\
\hline Scathophaga stercoraria & Diptera & Negative & Hind tibia length & $2.5-3.5 \mathrm{~mm}$ & Blanckenhorn (1997) \\
\hline Myrmeleon immaculatus & Neuroptera & Negative & Head width & $1.19-1.25 \mathrm{~mm}$ & Arnett \& Gotelli (1999a) \\
\hline Teleogryllus emma & Orthoptera & Negative & Head width & $5.3-7.4 \mathrm{~mm}$ & Masaki (1967) \\
\hline Omocestus viridulus & Orthoptera & Negative & Hind femur length & $9-14 \mathrm{~mm}$ & Berner \& Blanckenhorn (2006) \\
\hline Xanthippus corallipes & Orthoptera & Negative & Mass & $1.9-3.1 \mathrm{~g}$ & Ashby (1997) \\
\hline Bothrometopus brevis & Coleoptera & None & Body length & $3.7-4.2 \mathrm{~mm}$ & Chown \& Klok (2003) \\
\hline Phlebotomus papatasi & Diptera & None & Wing length & $2.26-2.52 \mathrm{~mm}$ & Belen et al. (2004) \\
\hline Sepsis cynipsea & Diptera & None & Head width & $0.9-1.0 \mathrm{~mm}$ & Blanckenhorn (1997) \\
\hline Drosophila robusta & Diptera & Positive & Wing length & $3.1-3.2 \mathrm{~mm}$ & Stalker \& Carson (1948) \\
\hline Bothrometopus elongtaus & Coleoptera & Positive & Body length & $2.8-3.4 \mathrm{~mm}$ & Chown \& Klok (2003) \\
\hline Bothrometopus parvulus & Coleoptera & Positive & Body length & $3.7-5.0 \mathrm{~mm}$ & Chown \& Klok (2003) \\
\hline Ectemnorhinus marioni & Coleoptera & Positive & Body length & $4.7-5.3 \mathrm{~mm}$ & Chown \& Klok (2003) \\
\hline Ectemnorhinus similis & Coleoptera & Positive & Body length & $5.9-8.0 \mathrm{~mm}$ & Chown \& Klok (2003) \\
\hline Nicrophorus investigator & Coleoptera & Positive & Elytron length & $8.8-9.8 \mathrm{~mm}$ & Smith et al. (2000) \\
\hline Sepidium dathan & Coleoptera & Positive & Elytron length & $7.5-12.5 \mathrm{~mm}$ & Krasnov et al. (1996) \\
\hline Drosophila buzzatii & Diptera & Positive & Thorax length & $*$ & Dahlgaard et al. (2001) \\
\hline Drosophila mediopunctata & Diptera & Positive & Size & $*$ & Bitner-Mathé \& Klaczko (1999) \\
\hline Lutzomyia intermedia & Diptera & Positive & Size & $0.31-0.40 \mathrm{~mm}$ & Marcondes et al. (1999) \\
\hline Musca domestica & Diptera & Positive & Size & $2.6 \mathrm{~mm}$ wing & Bryant (1977) \\
\hline Amegilla sapiens & Hymenoptera & Positive & Mass & $250-400 \mathrm{mg}$ & Stone $(1993)$ \\
\hline Apis mellifera & Hymenoptera & Positive & Forewing length & $8.3-9.5 \mathrm{~mm}$ & Ruttner et al. $(2000)$ \\
\hline Hemideina maori & Orthoptera & Positive & Head length & $10-22 \mathrm{~mm}$ & Koning \& Jamieson (2001) \\
\hline Melanoplus sanguinipes & Orthoptera & Positive & Mass & $0.2-0.6 \mathrm{~g}$ & Rourke $(2000)$ \\
\hline \multicolumn{6}{|l|}{ Interspecific } \\
\hline Nymphalidae & Lepidoptera & Curvilinear & Forewing length & $15-90 \mathrm{~mm}$ & Hawkins \& DeVries (1996) \\
\hline Pieridae & Lepidoptera & Negative & Forewing length & $10-40 \mathrm{~mm}$ & Hawkins \& DeVries (1996) \\
\hline Riodinidae & Lepidoptera & None & Forewing length & $10-30 \mathrm{~mm}$ & Hawkins \& DeVries (1996) \\
\hline Papilionidae & Lepidoptera & Positive & Forewing length & $30-70 \mathrm{~mm}$ & Hawkins \& DeVries (1996) \\
\hline \multicolumn{6}{|l|}{ Assemblage } \\
\hline Curculionidae & Coleoptera & Curvilinear & Body length & $3.7-8.5 \mathrm{~mm}$ & Chown \& Klok (2003) \\
\hline Insects & Insecta & Curvilinear & Length & $*$ & Janzen et al. (1976) \\
\hline Curculionidae & Coleoptera & Negative & Body length & $3.7-5.1 \mathrm{~mm}$ & Chown \& Klok (2003) \\
\hline Hegeter sp. & Coleoptera & Negative & Size & $*$ & De Los Santos et al. (2000) \\
\hline
\end{tabular}

temperature thresholds for growth $\left(\mathrm{TT}_{\mathrm{G}}\right)$ and development $\left(\mathrm{TT}_{\mathrm{D}}\right)$, and that the relative benefits of changes in these values are dependent on season length. This makes their model much more like the adaptive explanations discussed below. A further constraint model concerns interactions between whole-organismal and cellular oxygen supply (Makarieva et al., 2005). In this model, mass-specific metabolic rate increases more rapidly with temperature than does cellular metabolic flux. To maintain energy budget, cell size must decline with increasing temperature. Presuming constant cell number (which is by no means a certainty, see review in Chown \& Gaston, 1999), declining cell size should lead to declining body size. Alternatively, if metabolic rate is held constant, via adaptive differentiation among populations, larger size can be achieved by increasing whole-organismal metabolic flux and cell size. Using similar arguments and assuming constant minimum metabolic rates, this model also proposes a constraint explanation for interspecific size increases with temperature in terrestrial organisms, but the converse in aquatic ones (Makarieva et al., 2005). The authors also argue that their intraspecific model is superior to those which require consideration of seasonality, because there is apparently no cost of extension of life cycles to several years at high latitudes, and because no quantitative approach has been developed to demonstrate how changes in season length might effect changes in body size.

Amongst the adaptive explanations, those based on von Bertalanffy's growth equation have generally been 
rejected owing to their logical problems (Day \& Taylor, 1997; Kozłowski et al., 2004; Makarieva, Gorshkov \& Li, 2004), and lack of empirical support for their predictions (Angilletta \& Dunham, 2003). Perhaps the simplest of the remaining explanations, and one that has not typically been formulated numerically, is the starvation resistance (or more generally, resistance) hypothesis. Although originally used in an interspecific context, it can be applied just as readily intraspecifically (e.g. Stillwell et al., 2007). The idea essentially posits that large individuals at higher latitudes may be better able to survive starvation (or desiccation) than small individuals, hence species should tend to be larger at high latitudes (Cushman et al., 1993). One way in which this might occur is if the scaling of maintenance metabolic rate over winter has a lower exponent than the scaling of reserve storage. Such relative scaling does not seem implausible, and may even explain why colony size clines are found in some colonial insects (Kaspari \& Vargo, 1995; but see also Porter \& Hawkins, 2001). When examined from a scaling perspective, the starvation resistance hypothesis is readily identified as a specific case of a more general set of optimal resource allocation models (Kozłowski et al., 2004).

If these resource allocation models are considered together with models explaining sawtooth clines in size (Roff, 1980), they can provide a comprehensive explanation for both increases and declines in size with latitude and altitude in the context of changes in both temperature and season length. The relative independence of season length and temperature as factors influencing size, and the significance of generation time relative to season length in determining whether season length or temperature will have the most significant influence on size, was mooted originally by several authors (Nylin \& Gotthard, 1998; Chown \& Gaston, 1999), and has now garnered considerable empirical support (Fischer \& Fiedler, 2002; Chown \& Klok, 2003; Blanckenhorn \& Demont, 2004).

In essence, the combined model may be described as follows. Assume simple switching and growth curves for a univoltine insect, where the adult ages (although it can be ignored here, tissue repair and maintenance will make a difference to the form of the growth and switching curves; Kozłowski et al., 2004), and dies at the end of the season (Fig. 9). Under season length $T$, switching curve $a$, and growth curve $A$, optimal body size is $A^{\prime}$. At this size resources should be switched from growth to reproduction (see Kozłowski et al., 2004). Assume now that season length declines by some increment ( $T$ to $T-1$ ) because of a poleward shift in latitude. Because life expectancy is zero at the end of the season, the switching curve shifts to the left $(b)$, and given the same growth rate, optimal final size is reduced to $A^{\prime \prime}$. Experimental reductions in nutrient quality or availability typically result in reduced growth rate and size (including reduced critical weight), presumably via insulin signalling, so demonstrating the proximate physiological path. It is also simple to see the size-related fitness advantages associated with an increase in development time should season length increase (from $T-1$ to $T$ ), as might be

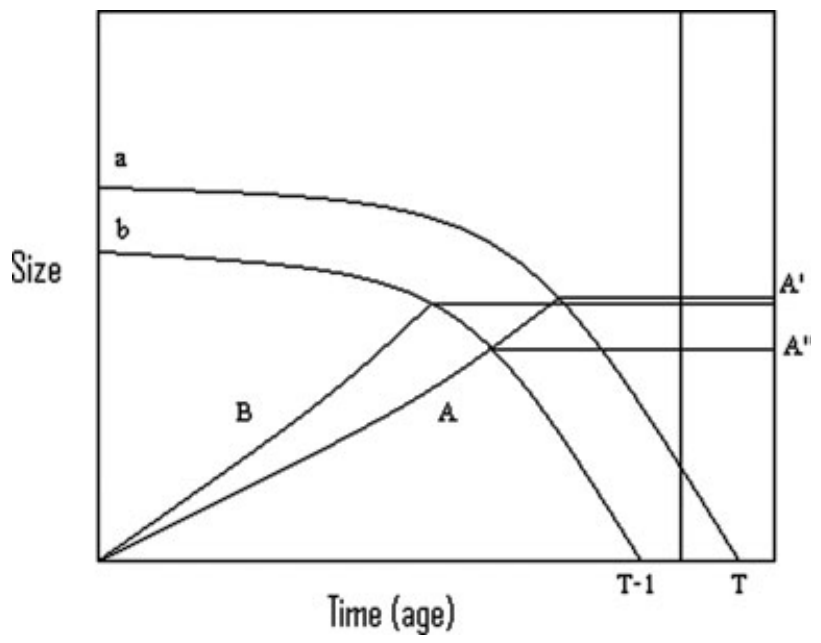

Fig. 9. Switching curve and growth curves for a model species (after Kozłowski et al., 2004). The switching curves $a$ and $b$ show where the switch should be from growth to reproduction and decline to zero at the end of the season. Two growth curves $A$ and $B$ are also shown. A decline in season length from $T$ to $T-1$ will mean that the switching curve must shift to the left, which with constant growth rate will result in a decline in body size $\left(A^{\prime}\right.$ to $\left.A^{\prime \prime}\right)$. An increase in growth rate $(A$ to $B)$ can compensate for the change in switching curve, but this has fitness implications. Increases in season length from $T-1$ to $T$ should result in an increase in size (although reductions in growth rate are not uncommon). This size increase will cease when the fitness benefits of a second generation outweigh those of large size as in Roff's (1980) model.

expected if moving towards the equator. However, as Roff (1980) has shown, there is a point at which the fitness advantage of large size is outweighed by the advantage of the addition of a second generation. Size then declines in the first tooth of a saw-tooth pattern because of the reduction in time for growth (i.e. there is a substantial change to the switching curve). As season length increases so additional generations can be added, each time with a declining reduction in development period, and so in body size. Once there is no longer any decline in development period with the addition of generations, the population is essentially composed of multivoltine, short-lived individuals living in a seasonal environment.

For multivoltine animals, Kozłowski et al.'s (2004) models for aseasonal conditions apply because they perceive reduced seasonality owing to the fast life cycle relative to the season length. These models are based on temperaturerelated differences in the body size-dependence of resource acquisition rate and metabolic rate (so giving rise to sizerelated changes in production rate), and the influence of mortality rate and its temperature dependence on optimal size. Under a wide range of conditions, and assuming several different forms of change in the coefficients and exponents of the size dependence of acquisition rate and metabolic rate, increases in size with declining temperature are optimal. Moreover, from a simple, proximate physiological 
Table 3. Predictions of hypotheses proposed to explain spatial size variation in insects

\begin{tabular}{|c|c|c|c|c|c|}
\hline Hypothesis & I & II & III & IV & $\mathrm{V}$ \\
\hline Description & $\begin{array}{l}\text { Proximate biophysical } \\
\text { model }^{1}\end{array}$ & $\begin{array}{l}\text { Temperature threshold } \\
\text { hypothesis }^{2}\end{array}$ & $\begin{array}{l}\text { Optimal resource } \\
\text { allocation model }^{3}\end{array}$ & $\begin{array}{l}\text { Minimum metabolic } \\
\text { rate }^{4}\end{array}$ & $\begin{array}{l}\text { Starvation } \\
\quad \text { resistance }\end{array}$ \\
\hline Size cline & + & $-/+$ & $-/+$ & $-/+$ & + \\
\hline $\begin{array}{l}\text { Differences in scaling of } \\
\text { rates }\end{array}$ & No & No & Yes & No & Yes \\
\hline $\begin{array}{l}\text { Relationship between } \\
\text { length of } \\
\text { unfavourable season } \\
\text { and size }\end{array}$ & No & - when cline - & - when cline - & No & + \\
\hline Larval mortality factors & No & No & Yes & No & No \\
\hline $\begin{array}{l}\text { Constant versus variable } \\
\text { cell number }\end{array}$ & No & No & No & Yes & No \\
\hline Sex-related differences & No & Yes & Yes & No & Yes \\
\hline
\end{tabular}

${ }^{1}$ Van der Have \& de Jongh (1996); ${ }^{2}$ Walters \& Hassall (2006); ${ }^{3}$ Kozłowski et al. (2004); ${ }^{4}$ Makarieva et al. (2005); ${ }^{5}$ Cushman et al. $(1993)$

perspective, declining temperature prolongs the ICG and developmental time, in an exponential manner (leaving the critical weight unaffected), and leads to a linear decline in growth rate. The outcome is a decline in body size with increasing temperature under a wide range of conditions (see Section II and Davidowitz \& Nijhout, 2004). The range of conditions under which such negative relationships between size and temperature are found might be wider than Kozłowski et al. (2004) or Davidowitz \& Nijhout (2004) suggested because countergradient variation, with shorter development times leading to large final size, is not uncommon in insects (Ayres \& Scriber, 1994; James et al., 1995; Arendt, 1997; Blanckenhorn \& Demont, 2004). However, which of the factors determining adult size (e.g. growth rate, duration of ICG, critical weight) are the subjects of selection has not yet been investigated.

A notable, and supported, empirical prediction of the optimal resource allocation model is a relationship between the direction of size clines and body size: smaller species with relatively faster development times that are unlikely to face nutritional constraints should tend to show Bergmann size clines, and indeed this is what has been found (Chown \& Gaston, 1999; Blanckenhorn \& Demont, 2004). Moreover, seasonal size variation is typical of such species too, and is almost by definition not applicable to species that do not have multiple generations annually. Nonetheless, some studies do not find support for the significance of variation in season length for variation in final adult size (Cabanita \& Atkinson, 2006). Moreover, others have suggested that direct selection on traits that have different responses to temperature, such as wing length and thorax size in Drosophila melanogaster, may explain clinal variation in adult size (Hoffmann et al., 2007).

If the resistance hypothesis (starvation or desiccation) is not subsumed within the resource allocation models, at least five models have been proposed to account for intraspecific clinal variation in adult size (Table 3). Most of these models predict some kind of relationship between size and temperature, and most of the predictions can, at least to some extent, be accommodated within what is known of the proximate, physiological factors affecting final adult size (see Section II). Therefore, these models may prove difficult to distinguish empirically. Indeed, no studies to date have attempted to do so, either from a strong inference perspective, or using an information theoretic approach. Nonetheless, the models all make a variety of ancillary predictions which would render them amenable to such approaches (Table 3). The proximate biophysical model and starvation resistance hypothesis predict only an increase in size with latitude/altitude. They may be distinguished by the fact that the former makes no prediction about the scaling of metabolic rate versus resource stores. If only phenotypic data on size are available, then the former does not make any prediction regarding season length, whereas the latter predicts a positive relationship between length of the unfavourable season and size. The temperature threshold and optimal resource allocation models make the opposite prediction. However, they can be distinguished by the fact that the latter predicts a strong influence of mortality factors on size. The minimum metabolic rate model predicts constant versus varying cell numbers depending on the cline and can therefore readily be separated from the other hypotheses, especially given that cell size proxies (ommatidia, wing cells) (e.g. Blanckenhorn \& Llaurens, 2005; Chown et al., 2007) can be readily assessed. The proximate biophysical model and minimum metabolic rate models make no prediction for difference among the sexes, whereas such differences are implicit in the other models.

Of course, few of the explanations for size clines, and even fewer of the tests thereof make an attempt to couple the evolutionary ecological aspects of these models with the proximate physiological factors affecting size variation. This is perhaps the weakest area of the field at present. Whilst not all systems will lend themselves to such investigation, explicit coupling of field and laboratory investigations of model species (recognizing that differences may sometimes arise between the field and laboratory-Fairbairn, 2005; Kingsolver, 2007) and nonmodel species will help demonstrate which explanations for 
size variation are likely to be the most general (see also Feder, 2007). Moreover, it should also be recognized that, at least at the intraspecific level, more than one set of circumstances might lead to spatial variation in size. After all, animals have to contend with variation in diet, water availability, temperature, and predators simultaneously (Elton, 1930). In consequence, it is too early yet to call off the documentation of intraspecific spatial variation in insect adult size, especially if this is undertaken either in the context of an explicit, strong inference assessment of the explanations for size variation, or in the context of how intraspecific variation relates to patterns at the interspecific and assemblage levels (see also Gaston et al., 2008).

\section{GONGLUSIONS}

(1) Much is known about the way in which natural selection leads to size variation at the individual level, how this translates to sexual size dimorphism, and how, in turn, individual-level variation leads to clinal variation within and between species and among assemblages at large scales.

(2) Despite this considerable body of theoretical and empirical work, several fundamental aspects of large-scale size variation in insects remain poorly understood. For example, individual (i.e. populationlevel) body size frequency distributions remain relatively poorly investigated. Likewise, body mass variation across the insects as a whole and within each of the orders has not been thoroughly documented. Indeed, how variation is partitioned at various levels of the taxonomic hierarchy, or how significant is the phylogenetic signal in body mass variation remains unclear.

(3) To a large extent this situation is a consequence of the fact that mass data are concealed within a wide range of papers. One solution would be the development of an online database for standardized insect body size data (for example length, mass and wingspan, and their variances). Such online databases are common in the fields of genomics and proteomics, and no good reason exists why the same approach should not be developed for macroecology.

(4) Investigations of clinal variation in size also need to make a clearer distinction between intraspecific, interspecific and assemblage-level analyses. Whilst these three levels can be thought of as different elements of a species by sites matrix (Gaston et al., 2008), this is rarely done. Nonetheless, such a distinction is necessary because both the methods required to document the patterns and the mechanisms underlying size variation (or lack of it) differ at each of these levels, although obviously what happens at one level may influence the others.

(5) At the intraspecific level, a relatively neglected component of research is the role of plasticity in generating and maintaining size clines relative to the importance of specialist phenotypes (see Angilletta, 2009 for a more general review). Moreover, a strong inference approach, or one using model selection based on information theory (see e.g. Johnson \& Omland, 2004; Angilletta, 2009) sorely needs to be applied to the question of the mechanism underlying intraspecific clines in body size. At present, several competing hypotheses exist to explain clinal variation, yet few studies have attempted simultaneously to assess these.

(6) Several other challenges remain. Of these, two strike us as most significant. First, the mechanistic basis by which oxygen concentration might influence insect size is not well understood. Whilst it is assumed that limits to diffusion and convection are the basis of oxygen-related size variation, recent empirical work suggests that the situation may be more complex (e.g. Klok \& Harrison, 2009). In addition, oxygen limitation of geographic range size, and a positive relationship between body size and range size, might explain the disappearance of giant insects. A more direct physiological mechanism might do likewise, as might a simple sampling mechanism. Again, these alternatives are rarely explored simultaneously. Second, few studies have sought to determine whether other macroecological patterns typical of vertebrates, such as the Island rule (Palmer, 2002), apply to insects. If macroecological patterns are to be considered general, then they should apply to insects as much as to other taxa.

\section{AGKNOWLEDGEMENTS}

We are grateful to Wolf Blanckenhorn, Zoe Davies, Michelle Greve, Susana Clusella-Trullas and an anonymous referee for comments on a previous version of the manuscript, and Michelle Greve, Ulrike Irlich, and Pat Johnson for assistance. Jeanne Gouws kindly provided access to her unpublished M.Sc. thesis work. K.J.G. holds a Royal Society-Wolfson Research Merit Award.

\section{REFERENGES}

Abouhief, E. \& Fairbairn, D. J. (1997). A comparative analysis of allometry for sexual size dimorphism: assessing Rensch's rule. American Naturalist 149, 540-562.

Addo-Bediako, A., Chown, S. L. \& Gaston, K.J. (2001). Revisiting water loss in insects: a large scale view. Fournal of Insect Physiology 47, 1377-1388.

Agosta, S. J. \& Janzen, D. H. (2005). Body size distributions of large Costa Rican dry forest moths and the underlying relationship between plant and pollinator morphology. Oikos 108, 183-193.

Alcock, J. (1984). Long-term maintenance of size variation in populations of Centris pallida (Hymenoptera: Anthophoridae). Evolution 38, 220-223. 
Alcock, J., Simmons, L. W. \& Beveridge, M. (2005). Seasonal change in offspring sex and size in Dawson's burrowing bees (Amegilla dawesoni) (Hymenoptera: Anthophorini). Ecological Entomology 30, 247-254.

Alcock, J., Simmons, L. W. \& Beveridge, M. (2006). Does variation in female body size affect nesting success in Dawson's burrowing bee, Amegilla dawsoni (Apidae: Anthophorini)? Ecological Entomology 31, 352-357.

Alexander, R. D. \& Bigelow, R. S. (1960). Allochronic speciation in field crickets, and a new species, Acheta veletis. Evolution 14, 334-346.

Alpatov, W. W. (1929). Biometrical studies on variation and races of the honey bee, Apis mellifera. Quarterly Review of Biology 4, 1-58.

Angilletta, M.J. (2009). Thermal Adaptation. A Theoretical and Empirical Synthesis. Oxford University Press, Oxford.

Angilletta, M.J. \& Dunham, A. E. (2003). The temperaturesize rule in ectotherms: simple evolutionary explanations may not be general. American Naturalist 162, 332-342.

Arendt, J. D. (1997). Adaptive intrinsic growth rates: an integration across taxa. Quarterly Review of Biology 72, 149-177.

Arnett, A. E. \& Gotelli, N.J. (1999a). Bergmann's rule in the ant lion Myrmeleon immaculatus DeGeer (Neuroptera: Myrmeleontidae): geographic variation in body size and heterozygosity. Fournal of Biogeography 26, 275-283.

Arnett, A. E. \& Gotelli, N. J. (1999b). Geographic variation in life-history traits of the ant lion, Myrmeleon immaculatus: evolutionary implications of Bergmann's rule. Evolution 53, 1180-1188.

Arnett, A. E. \& Gotelli, N. J. (2003). Bergmann's rule in larval ant lions: testing the starvation resistance hypothesis. Ecological Entomology 28, 645-650.

Ashby, P. D. (1997). Conservation of mass-specific metabolic rate among high- and low-elevation populations of the acridid grasshopper Xanthippus corallipes. Physiological Zoology 70, 701-711.

Ashton, K. G., Tracy, M. C. \& De Queiroz, A. (2000). Is Bergmann's rule valid for mammals? American Naturalist 156, 390-415.

Atkinson, D. (1994). Temperature and organism size-a biological law for ectotherms? Advances in Ecological Research 25, 1-58.

Ayres, M. P. \& Scriber, J. M. (1994). Local adaptation to regional climates in Papilio canadensis (Lepidoptera: Papilionidae). Ecological Monographs 64, 465-482.

Azevedo, R. B. R., French, V. \& Partridge, L. (1996). Thermal evolution of egg size in Drosophilia melanogaster. Evolution 50, 2338-2345.

Azevedo, R. B. R., James, A. C., Mccabe, J. \& Partridge, L. (1998). Latitudinal variation of wing:thorax size ratio and wingaspect ratio in Drosophilia melanogaster. Evolution 52, 1353-1362.

BAвA, M. (1992). Oviposition habits of Simulium kawamurae (Diptera, Simuliidae) with reference to seasonal changes in body size and fecundity. Fournal of Medical Entomology 29, 603-610.

BARLOw, N. D. (1994). Size distribution of butterfly species and the effect of latitude on species sizes. Oikos 71, 326-332.

Bartholomew, G. A. \& Epting, R. J. (1975). Allometry of postflight cooling rates in moths: a comparison with vertebrate homeotherms. Fournal of Experimental Biology 63, 603-613.

Basset, Y. (1997). Species abundance and body size relationships in insect herbivores associated with New Guinea forest trees, with particular reference to insect host-specificity. In Canopy
Arthropods (eds N. E. Stork, J. Adis \& R. K. Didham), pp. 237-264, Chapman and Hall, London.

Basset, Y. \& Kitching, R. L. (1991). Species number, species abundance and body length of arboreal arthropods associated with an Australian rainforest tree. Ecological Entomology 16, 391-402.

Bede, J. C., Mcneil, J. N. \& Tobe, S. S. (2007). The role of neuropeptides in caterpillar nutritional ecology. Peptides 28, 185-196.

Belen, A., Altern, B. \& Aytekin, A. M. (2004). Altitudinal variation in morphometric and molecular characteristics of Phlebotomus papatasi populations. Medical and Veterinary Entomology 18, 343-350.

Benke, A. G., Huryn, A. D., Smock, L. A. \& Wallace, J. B. (1999). Length-mass relationships for freshwater macroinvertebrates in North America with particular reference to the southeastern United States. Fournal of the North American Benthological Society 18, 308-343.

Berner, D. \& Blanckenhorn, W. U. (2006). Grasshopper ontogeny in relation to time constraints: adaptive divergence and stasis. Fournal of Animal Ecology 75, 130-139.

Berner, D., Blanckenhorn, W. U. \& Körner, C. (2005). Grasshoppers cope with low host quality by compensatory feeding and food selection: N limitation challenged. Oikos 111, 525-533.

Berrigan, D. \& Charnov, E. L. (1994). Reaction norms for age and size at maturity in response to temperature: a puzzle for life historians. Oikos 70, 474-478.

Bitner-Mathé, B. C. \& Klaczko, L. B. (1999). Size and shape heritability in natural populations of Drosophila mediopunctata: temporal and microgeographical variation. Genetica 105, 35-42.

Blackburn, T. M. \& Gaston, K. J. (1994a). Animal body size distributions change as more species are described. Proceedings of the Royal Society of London B 257, 293-297.

Blackburn, T. M. \& Gaston, K. J. (1994b). The distribution of body sizes of the world's bird species. Oikos 70, 127-130.

Blackburn, T. M. \& Gaston, K. J. (1998). Some methodological issues in macroecology. American Naturalist 151, 68-83.

Blackburn, T. M. \& Gaston, K.J. (1999). The relationship between animal abundance and body size: a review of the mechanisms. Advances in Ecological Research 28, 181-210.

Blackburn, T. M. \& Gaston, K. J. (2001). Linking patterns in macroecology. Fournal of Animal Ecology 70, 338-352.

BlackBurn, T. M. \& GASTON, K. J. (2003). Introduction: why macroecology? In Macroecology: Concepts and Consequences (eds T. M. Blackburn \& K. J. Gaston), pp. 1-14, Blackwell Science, Oxford.

Blackburn, T. M., Gaston, K.J. \& Loder, N. (1999). Geographic gradients in body size: a clarification of Bergmann's rule. Diversity and Distributions 5, 165-174.

Blake, S., Foster, G. N., Eyre, M. D. \& Luff, M. L. (1994). Effects of habitat type and grassland management practices on the body size distribution of carabid beetles. Pedobiologia 38, 502-512.

BLANCKENHORN, W. U. (1997). Altitudinal life history variation in the dung flies Scathophaga stercoraria and Sepsis cynipsea. Oecologia 109, 342-352.

Blanckenhorn, W. U. (1999). Different growth responses to temperature and resource limitation in three fly species with similar life histories. Evolutionary Ecology 13, 395-409. 
Blanckenhorn, W. U. (2000a). Temperature effects on egg size and their fitness consequences in the yellow dung fly Scathophaga stercoraria. Evolutionary Ecology 14, 627-643.

Blanckenhorn, W. U. (2000b). The evolution of body size: what keeps organisms small? Quarterly Review of Biology 75, 385-407.

Blanckenhorn, W. U. (2005). Behavioral causes and consequences of sexual size dimorphism. Ethology 111, 977-1016.

Blanckenhorn, W. U. \& Demont, M. (2004). Bergmann and converse Bergmann latitudinal clines in arthropods: two ends of a continuum? Integrative and Comparative Biology 44, 413-424.

Blanckenhorn, W. U., Dixon, A. F. G., Fairbairn, D. J., Foellmer, M. W., Gibert, P., Van Der Linde, K., Meier, R., Nylin, S., Pitnick, S., Schoff, G., Signorelli, M., Teder, T. \& Wiklund, C. (2007a). Proximate causes of Rensch's rule: does sexual size dimorphism in arthropods result from sex differences in development time? American Naturalist 167, 245-257.

Blanckenhorn, W. U., Fanti, J. \& Reim, G. (2007b). Sizedependent energy reserves, energy utilization and longevity in the yellow dung fly. Physiological Entomology 32, 372-381.

Blanckenhorn, W. U. \& Llaurens, V. (2005). Effects of temperature on cell size and number in the yellow dung fly Scathophaga sterocoraria. Fournal of Thermal Biology 30, 213-219.

Blanckenhorn, W. U., Stillwell, R. C., Young, K. A., Fox, C. W. \& Ashton, K. G. (2006). When Rensch meets Bergmann: does sexual size dimorphism change systematically with latitude? Evolution 60, 2004-2011.

Brändle, M., Stadler, J. \& Brandl, R. (2000). Body size and host range in European Heteroptera. Ecography 23, 139-147.

Braun, S. D., Jones, T. H. \& Perner, J. (2004). Shifting average body size during regeneration after pollution-a case study using ground beetle assemblages. Ecological Entomology 29, 543-554.

Brehm, G. \& Fiedler, K. (2004). Bergmann's rule does not apply to geometrid moths along an elevational gradient in an Andean montane rain forest. Global Ecology and Biogeography 13, 7-14.

Brennan, J. M. \& FAirbairn, D. J. (1995). Clinal variation in morphology among eastern populations of the waterstrider, Aquarius remigis Say (Hemiptera: Gerridae). Biological Fournal of the Linnean Society 54, 151-171.

Brown, J. H. (1995). Macroecology. University of Chicago Press, Chicago.

Brown, J. H. (1999). Macroecology: progress and prospect. Oikos 87, 3-14.

Brown, J. H., Gillooly, J. F., Allen, A. P., Savage, V. \& West, G. B. (2004). Toward a metabolic theory of ecology. Ecology 85, 1771-1789.

Brown, J. H., Marquet, P. A. \& Taper, M. L. (1993). Evolution of body size: consequences of an energetic definition of fitness. American Naturalist 142, 573-584.

Brown, J. H. \& Maurer, B. A. (1989). Macroecology: The division of food and space among species on continents. Science 243, 1145-1150.

Bryant, E. H. (1977). Morphometric adaptation of the housefly, Musca domestica L., in the United States. Evolution 31, 580-596.

Cabanita, R. \& Atrinson, D. (2006). Seasonal time constraints do not explain exceptions to the temperature size rule in ectotherms. Oikos 114, 431-440.

Cabrero-Sañudo, F. J. \& Lobo, J. M. (2003). Estimating the number of species not yet described and their characteristics: the case of Western Palaearctic dung beetle species (Coleoptera, Scarabaeoidea). Biodiversity and Conservation 12, 147-166.
Calboli, F. C. F., Gilchrist, G. C. \& Partridge, L. (2003). Different cell size and cell number contribution in two newly established and one ancient body size cline of Drosophila subobscura. Evolution 57, 566-573.

Casey, T. M., May, M. L. \& Morgan, K. R. (1985). Flight energetics of euglossine bees in relation to morphology and wing stroke frequency. Fournal of Experimental Biology 116, 271-289.

Cerdá, X. \& Retana, J. (2000). Alternative strategies by thermophilic ants to cope with extreme heat: individual versus colony level traits. Oikos 89, 155-163.

Chown, S. L. (1997). Speciation and rarity: separating cause from consequence. In The Biology of Rarity (eds. W. E. Kunin and K. J. Gaston), pp. 91-109, Chapman \& Hall, London.

Chown, S. L. (2001). Physiological variation in insects: hierarchical levels and implications. Fournal of Insect Physiology 47, 649-660.

Chown, S. L., Addo-Bediako, A. \& Gaston, K.J. (2002). Physiological variation in insects: large-scale patterns and their implications. Comparative Biochemistry and Physiology B 131, 587-602.

Chown, S. L. \& Gaston, K.J. (1997). The species-body size distribution: energy, fitness and optimality. Functional Ecology 11, 365-375.

Chown, S. L. \& Gaston, K. J. (1999). Exploring links between physiology and ecology at macro-scales: the role of respiratory metabolism in insects. Biological Reviewes 74, 87-120.

Chown, S. L. \& KLok, C. J. (2003). Altitudinal body size clines: latitudinal effects associated with changing seasonality. Ecography 26, 445-455.

Chown, S. L., Marais, E., Terblanche, J. S., Klok, C. J., Lighton, J. R. B. \& Blackburn, T. M. (2007). Scaling of insect metabolic rate is inconsistent with the nutrient supply network model. Functional Ecology 21, 282-290.

Chown, S. L., Scholtz, C. H., Klok, G.J., Joubert, F. J. \& Coles, K. S. (1995). Ecophysiology, range contraction and survival of a geographically restricted African dung beetle (Coleoptera: Scarabaeidae). Functional Ecology 9, 30-39.

Chown, S. L. \& Steenkamp, H. E. (1996). Body size and abundance in a dung beetle assemblage: optimal mass and the role of transients. African Entomology 4, 203-212.

Chown, S. L. \& Terblanche, J. S. (2007). Physiological diversity in insects: ecological and evolutionary contexts. Advances in Insect Physiology 33, 50-152.

Cichó, M. \& KozŁowski, J. (2000). Ageing and typical survivorship curves result from optimal resource allocation. Evolutionary Ecology Research 2, 857-870.

Coetzee, B. W. T., Van Rensburg, B. J., Robertson, M. P. (2007). Invasion of grasslands by silver wattle, Acacia dealbata (Mimosaceae) alters beetle (Coleoptera) assemblage structure. African Entomology 15, 328-339.

Colbo, M. H. \& Porter, G. N. (1979). The interaction of rearing temperature and food supply on the life history of two species of Simuliidae (Diptera). Canadian Fournal of Zoology 57, 301-306.

Colinet, H., Vernon, P. \& Hance, T. (2007). Does thermalrelated plasticity in size and fat reserves influence supercooling abilities and cold-tolerance in Aphidius colemani (Hymenoptera: Aphidiinae) mummies? Fournal of Thermal Biology 32, 374-382.

Currano, E. D., Wilf, P., Wing, S. L., Labandeira, G. G., Lovelock, E. C. \& Royer, D. L. (2008). Sharply increased 
insect herbivory during the Paleocene-Eocene Thermal Maximum. Proceedings of the National Academy of Sciences of the U.S.A 105, 1960-1964.

Cushman, J. H., Lawton, J. H. \& Manly, B. F. J. (1993). Latitudinal patterns in European ant assemblages: variation in species richness and body size. Oecologia 95, 30-37.

D’Amico, L. J., Davidowitz, G. \& Nijhout, H. F. (2001). The developmental and physiological basis of body size evolution in an insect. Proceedings of the Royal Society of London B 268, 1589-1593.

DahlgaArd, J., Hasson, E. \& Loeschcke, V. (2001). Behavioral differentiation in oviposition activity in Drosophila buzzatii from highland and lowland populations in Argentina: plasticity or thermal adaptation? Evolution 55, 738-747.

Daly, H. V., Hoelmer, K. \& Gambino, P. (1991). Clinal geographic variation in feral honey bees in California, USA. Apidologie 22, 591-609.

Darveau, G. A., Hochachka, P. W., Roubik, D. W. \& Suarez, R. K. (2005a). Allometric scaling of flight energetics in orchid bees: evolution of flux capacities and flux rates. Fournal of Experimental Biology 208, 3593-3602.

Darveau, C. A., Hochachka, P. W., Welch, K. C., Roubik, D. W. \& SuArez, R. K. (2005b). Allometric scaling of flight energetics in Panamanian orchid bees: a comparative phylogenitic approach. Fournal of Experimental Biology 208, 3581-3591.

David, J. R. \& Bocquet, C. (1975). Similarities and differences in latitudinal adaptation of two Drosophila sibling species. Nature 257, 588-591.

David, J. R., Gibert, P., Gravot, E., Petavy, G., Morin, J.-P., Karan, D. \& Moreteau, B. (1997). Phenotypic plasticity and developmental temperature in Drosophila: analysis and significance of reaction norms of morphometrical traits. Fournal of Thermal Biology 22, 441-451.

Davidowitz, G., D’amico, L. J. \& Nijhout, H. F. (2003). Critical weight in the development of insect body size. Evolution and Development 5, 188-197.

Davidowitz, G., D’amico, L. J. \& Nijhout, H. F. (2004). The effects of environmental variation on a mechanism that controls insect body size. Evolutionary Ecology Research 6, 49-62.

Davidowitz, G. \& Nijhout, H. F. (2004). The physiological basis of reaction norms: the interaction among growth rate, the duration of growth and body size. Integrative and Comparative Biology 44, 443-449.

Davidowitz, G., Roff, D. A. \& Nijhout, H. F. (2005). A physiological perspective on the response of body size and development time to simultaneous directional selection. Integrative and Comparative Biology 45, 525-531.

Davies, K. F., Margules, C. R. \& Lawrence, J. F. (2000). Which traits predict population declines in experimental forest fragments? Ecology 81, 1450-1461.

Day, T. \& Rowe, L. (2002). Developmental thresholds and the evolution of reaction norms for age and size at life-history transitions. American Naturalist 159, 338-350.

DAy, T. \& TAYloR, P. D. (1997). Von Bertalanffy's growth equation should not be used to model age and size at maturity. American Naturalist 149, 381-393.

De Block, M., Mсpeek, M. A. \& Stoks, R. (2008). Life history plasticity to combined time and biotic constraints in Lestes damselflies from vernal and temporary ponds. Oikos 117, 908-916.
De Block, M. \& Stoks, R. (2008). Compensatory growth and oxidative stress in a damselfly. Proceedings of the Royal Society of London B 275, 781-785.

De Jong, G., and T. M. Van Der Have. (2008). Temperature dependence of development rate, growth rate and size: from biophysics to adaptation. In Phenotypic Plasticity of Insects. Mechanisms and Consequence (eds D. W. Whitman \& T. N. Ananthakrishnan, pp. 461 to 526, Science Publishers, Enfield, U.S.A.

Blackburn, T. M. \& Gaston, K. J. (2003). Introduction: why macroecology? In Macroecology: Concepts and Consequences (eds T. M. Blackburn \& K. J. Gaston), pp. 1-14, Blackwell Science, Oxford.

De los Santos, A., Gómez-gonzález, L. A., Alonso, C., Arbelo, C. D. \& De nicolás, J. P. (2000). Adaptive trends of darkling beetles (Col. Tenebrionidae) on environmental gradients on the island of Tenerife (Canary Islands). Fournal of Arid Environments 45, 85-98.

Dewitt, T.J. \& Scheiner, S. M. (2004). Phenotypic Plasticity. Functional and Conceptual Approaches. Oxford University Press, New York.

Dial, K. P. \& Marzluff, J. M. (1988). Are the smallest organisms the most diverse? Ecology 69, 1620-1624.

Didham, R. K., Hammond, P. M., Lawton, J. H., EggleTON, P. \& Stork, N. E. (1998). Beetle species responses to tropical forest fragmentation. Ecological Monographs 68, 295-323.

Dillon, M. E., Frazier, M. R. \& Dudley, R. (2006). Into thin air: physiology and evolution of alpine insects. Integrative and Comparative Biology 46, 49-61.

Diniz-Filho, J. A. F., Bini, L. M., Rodriguez, M. A., Rangel, T. F. L. V. B. \& Hawkins, B. A. (2007). Seeing the forest for the trees: partitioning ecological and phylogenetic components of Bergmann's rule in European Carnivora. Ecography 30, 598-608.

Diniz-Filho, J. A. F. \& Fowler, H. G. (1998). Honey ants (Genus Myrmecocystus macroecology: effects of spatial patterns on the relationship between worker body size and geographic range size. Environmental Entomology 27, 1094-1101.

Dixon, A. F. G. \& Hemptinne, J.-L. (2001). Body size distribution in predatory ladybird beetles reflects that of their prey. Ecology 82, $1847-1856$.

Dixon, A. F. G., Kindlmann, P. \& Jarošık, V. (1995). Body size distribution in aphids: relative surface area of specific plant structures. Ecological Entomology 20, 111-117.

Dubrovsky, E. B. (2005). Hormonal cross-talk in insect development. Trends in Endocrinology and Metabolism 16, 6-11.

Dudley, R. (1998). Atmospheric oxygen, giant paleozoic insects and the evolution of aerial locomotor performance. Fournal of Experimental Biology 201, 1043-1050.

Dudley, R. (2000a). The Biomechanics of Insect Flight. Form, Function, Evolution. Princeton University Press, Princeton.

DudLey, R. (2000b). The evolutionary physiology of animal flight: paleobiological and present perspectives. Annual Review of Physiology 62, $135-155$.

Eberhard, W. G. (2009). Static allometry and animal genitalia. Evolution 63, 48-66.

Edgar, B. A. (2006). How flies get their size: genetics and physiology. Nature Reviewes Genetics 7, 907-916.

ELDREDGE, N. (1986). Information, economics, and evolution. Annual Review of Ecology and Systematics 17, 351-369.

Elmes, G., Wardlaw, J. C., Nielsen, M. G., Kipyatkov, V. E., Lopatina, E. B., Radchenko, A. G. \& Barr, B. (1999). Site 
latitude influences respiration rate, fat content and the ability of worker ants to rear larvae: a comparison of Myrmica rubra (Hymenoptera: Formicidae) populations over their European range. European Fournal of Entomology 96, 117-124.

Elton, C. (1930). Animal Ecology and Evolution. Clarendon Press, Oxford.

Emlen, D. J. \& Allen, C. E. (2004). Genotype to phenotype: physiological control of trait size and scaling in insects. Integrative and Comparative Biology 43, 617-634.

Emlen, D. J., Lavine, L. C. \& Ewen-Campen, B. (2007). On the origin and evolutionary diversification of beetle horns. Proceedings of the National Academy of Sciences of the U.S.A 104(Suppl. 1): 8661-8668.

Emlen, D. J. \& Nijhout, H. F. (2000). The development and evolution of exaggerated morphologies in insects. Annual Review of Entomology 45, 661-708.

ERnsting, G. \& IsAaks, J. A. (1997). Effects of temperature and season on egg size, hatchling size and adult size in Notiophilus biguttatus. Ecological Entomology 22, 32-40.

ERnsting, G. \& IsAAKs, J. A. (2000). Ectotherms, temperature, and trade-offs: size and number of eggs in a carabid beetle. American Naturalist 155, 804-813.

Espadaler, X. \& Gómez, C. (2002). The species body-size distribution in Iberian ants is parameter independent. Vie et Milieu 52, 103-107.

Esperk, T., Tammaru, T., Nylin, S. \& Teder, T. (2007). Achieving high sexual size dimorphism in insects: females add instars. Ecological Entomology 32, 243-256.

Etienne, R. S. \& OlfF, H. (2004). How dispersal limitation shapes species-body size distributions in local communities. American Naturalist 163, 69-83.

Etilé, E. \& Despland, E. (2008). Developmental variation in the forest tent caterpillar: life history consequences of a threshold size for pupation. Oikos 117, 135-143.

Evans, E. W. (2000). Morphology of invasion: body size patterns associated with establishment of Coccinella septempunctata (Coleoptera: Coccinellidae) in western North America. European Journal of Entomology 97, 469-474.

Fagan, W. F., Siemann, E., Mitter, C., Denno, R. F., Huberty, A. F., Woods, H. A. \& Elser, J.J. (2002). Nitrogen in insects: implications for trophic complexity and species diversification. American Naturalist 160, 784-802.

FAIrbairn, D. J. (1997). Allometry for sexual size dimorphism: pattern and process in the coevolution of body size in males and females. Annual Review of Ecology and Systematics 28, 659-687.

FAIrbairn, D. J. (2005). Allometry for sexual size dimorphism: testing two hypotheses for Rensch's rule in the water strider Aquarius remigis. American Naturalist 166, S69-S84.

Feder, M. F. (2007). Key issues in achieving an integrated perspective on stress. Fournal of Biosciences 32, 433-440.

Feener, D. H., Lighton, J. R. B. \& Bartholomew, G. A. (1988). Curvilinear allometry, energetics and foraging ecology: a comparison of leaf-cutting ants and army ants. Functional Ecology 2, 509-520.

Finlay, B. J., Thomas, J. A., Mcgavin, G. G., Fenchel, T. \& Clarke, R. T. (2006). Self-similar patterns of nature: insect diversity at local to global scales. Proceedings of the Royal Society of London B 273, 1935-1941.

Fischer, K., Bauerfeind, S. S. \& Fiedler, K. (2006). Temperature-mediated plasticity in egg and body size in egg size-selected lines of a butterfly. Fournal of Thermal Biology 31, $347-354$

Fischer, K., Bot, A. N. M., Brakefield, P. M. \& Zwaan, B. J. (2003). Fitness consequences of temperature-mediated egg size plasticity in a butterfly. Functional Ecology 17, 803-810.

Fischer, K. \& Fiedler, K. (2002). Reaction norms for age and size at maturity in response to temperature: a test of the compound interest hypothesis. Evolutionary Ecology 16, 333-349.

Fischer, K., ZwaAn, B. J. \& Brakefield, P. M. (2002). How does egg size relate to body size in butterflies? Oecologia $\mathbf{1 3 1}$ 375-379.

Fox, C. W. \& Czesak, M. E. (2006). Selection on body size and sexual size dimorphism differs between host species in a seedfeeding beetle. Fournal of Evolutionary Biology 19, 1167-1174.

Frazier, M. R., Woods, H. A. \& Harrison, J. F. (2001). Interactive effects of rearing temperature and oxygen on the development of Drosophila melanogaster. Physiological and Biochemical Zoology 74, 641-650.

Gäde, G. \& Hoffmann, K. H. (2005). Neuropeptides regulating development and reproduction in insects. Physiological Entomology 30, 103-121.

Gahlhoff, J. E. JR. (1998). Smallest adult. http://ufbir.ifas.ufl. edu/chap38.htm

García-Barros, E. (2000). Body size, egg size, and their interspecific relationships with ecological and life history traits in butterflies (Lepidoptera: Papilionoidea, Hesperioidea). Biological Fournal of the Linnean Society 70, 251-284.

Gaston, K. J. (1988). The intrinsic rates of increase of insects of different sizes. Ecological Entomology 14, 399-409.

Gaston, K.J. (1991a). Body size and probability of description: the beetle fauna of Britain. Ecological Entomology 16, 505-508.

Gaston, K.J. (1991b). The magnitude of global insect species richness. Conservation Biology 5, 283-296.

Gaston, K. J. \& Blackburn, T. M. (2000). Pattern and Process in Macroecology. Blackwell Science, Oxford.

Gaston, K.J. \& Blackburn, T. M. (1994). Are newly described species small-bodied? Biodiversity Letters 2, 16-20.

Gaston, K. J. \& Blackburn, T. M. (1996). Global scale macroecology: interactions between population size, geographic range size and body size in Anseriformes. Fournal of Animal Ecology 65, 701-714.

Gaston, K.J. \& Blackburn, T. M. (2000). Pattern and Process in Macroecology. Blackwell Science, Oxford.

Gaston, K. J., Blackburn, T. M., Hammond, P. M. \& Stork, N. E. (1993). Relationships between abundance and body size: where do tourists fit? Ecological Entomology 18, 310-314.

Gaston, K.J., Blackburn, T. M. \& Spicer, J. I. (1998). Rapoport's rule: time for an epitaph? Trends in Ecology and Evolution 13, $70-74$.

Gaston, K. J. \& Chown, S. L. (1999). Geographic range size and speciation. In Evolution of Biological Diversity (eds. A. E. Magurran and R. M. May), pp. 236-259, Oxford University Press, Oxford.

Gaston, K. J., Chown, S. L. \& Evans, K. L. (2008). Ecogeographic rules: elements of a synthesis. Fournal of Biogeography 35, $483-500$

Gaston, K.J., Chown, S. L. \& Mercer, R. D. (2001). The animal species-body size distribution of Marion Island. Proceedings of the National Academy of Sciences of the U.S.A 98, 14493-14496. 
Gaston, K. J., Chown, S. L. \& Styles, C. V. (1997). Changing size and changing enemies: the case of the mopane worm. Acta Oecologica 18, 21-26.

Gaston, K. J. \& Lawton, J. H. (1988). Patterns in the distribution and abundance of insect populations. Nature 331, 709-712.

Gaston, K. J.， Reavey, D. \& Valladares, G. R. (1991). Changes in feeding habit as caterpillars grow. Ecological Entomology 16, 339-344.

Gauld, I. \& Bolton, B. (eds.) (1988). The Hymenoptera. British Museum (Natural History) \& Oxford University Press, London \& Oxford.

Gaunt, M. W. \& Miles, M. A. (2002). An insect molecular clock dates the origin of the insects and accords with palaeontological and biogeographic landmarks. Molecular Biology and Evolution 19, $748-761$.

Ghalambor, C. K., Mckay, J. K., Carroll, S. P. \& Reznick, D. N. (2007). Adaptive versus non-adaptive phenotypic plasticity and the potential for contemporary adaptation in new environments. Functional Ecology 21, 394- 407.

Gibbs, A. G., Chippindale, A. K. \& Rose, M. R. (1997). Physiological mechanisms of evolved desiccation resistance in Drosophila melanogaster. Fournal of Experimental Biology 200, 1821-1832.

Gilchrist, G. W. \& Huey, R. B. (2004). Plastic and genetic variation in wing loading as a function of temperature within and among parallel clines in Drosophila subobscura. Integrative and Comparative Biology 44, 461-470.

Gilchrist, G. W., Huey, R. B., Balanyá, J., Pascual, M. \& SERrA, L. (2004). A time series of evolution in action: a latitudinal cline in wing size in South American Drosophila subobscura. Evolution 58, 768-780.

GotThARD, K. (2004). Growth strategies and optimal body size in temperate Pararginii butterflies. Integrative and Comparative Biology 44, 471-479.

Gotthard, K., Nylin, S. \& Wiklund, C. (1999). Seasonal plasticity in two satyrine butterlfies: state-dependent decision making in relation to daylength. Oikos 84, 453-462.

Gotthard, K., Nylin, S. \& Wiklund, C. (2000). Individual state controls temperature dependence in a butterfly (Lassiommata maera). Proceedings of the Royal Society of London B 267, 589-593.

Gouws, E. J. (2007). Intraspecific Body Size Variation in Insects. M.Sc. Thesis, Stellenbosch University, Stellenbosch.

Grandchamp, A-C., Niemelä, J. \& Kotze, J. (2000). The effects of trampling on assemblages of ground beetles (Coleoptera, Carabidae) in urban forests in Helsinki, Finland. Urban Ecosystems 4, 321-332.

Green, A. J. (1999). Allometry of genitalia in insects and spiders: one size does not fit all. Evolution 53, 1621-1624.

Greenlee, K. J. \& Harrison, J. F. (2004). Development of respiratory function in the American locust Schistocerca americana I. Across-instar effects. Fournal of Experimental Biology 207, 497-508.

Greenlee, K. J. \& Harrison, J. F. (2005). Respiratory changes throughout ontogeny in the tobacco hornworm caterpillar, Manduca sexta. Fournal of Experimental Biology 208, 1385-1392.

Greenlee, K. J., Nebeker, C. \& Harrison, J. F. (2007). Body size-independent safety margins for gas exchange across grasshopper species. Fournal of Experimental Biology 210, 1288-1296.

Greve, M., Gaston, K. J., Van Rensburg, B. J. \& Chown, S. L. (2008). Environmental factors, regional body size distributions and spatial variation in body size of local avian assemblages. Global Ecology and Biogeography 17, 514-523.
Grimaldi, D. \& Engel, M. S. (2005). Evolution of the Insects. Cambridge University Press, Cambridge.

Grimbacher, P. S., Catterall, G. P. \& Kitching, R. L. (2008). Detecting the effects of environmental change above the species level with beetles in a fragmented tropical rainforest landscape. Ecological Entomology 33, 66-79.

Groeters, F. R. \& Shaw, D. D. (1996). Evidence for association of chromosomal form and development time from complex clines and geographic races in the grasshopper Caledia captiva (Orthoptera: Acrididae). Biological Fournal of the Linnean Society 59, 243-259.

Gullan, P. J. \& Cranston, P. S. (2005). The Insects: An Outline of Entomology. Blackwell Publishing, Oxford.

Gutiérrez, D. \& Menéndez, R. (1997). Patterns in the distribution, abundance and body size of carabid beetles (Coleoptera: Caraboidea) in relation to dispersal ability. Fournal of Biogeography 24, 903-914.

Hallas, R., Schiffer, M. \& Hoffmann, A. A. (2002). Clinal variation in Drosophila serrata for stress resistance and body size. Genetics Research 79, 141-148.

Hanks, L. M., Paine, T. D. \& Millar, J. G. (2005). Influence of the larval environment on performance and adult body size of the wood-boring beetle Phoracantha semipunctata. Entomologia Experimentalis et Applicata 114, 25-34.

HANSKi, I. \& CAmbefort, Y. (1991). Resource partitioning. In Dung Beetle Ecology (eds. I. Hanski and Y. Cambefort), pp. 330-349, Princeton University Press, Princeton.

Haro, R. J., Edley, K. \& Wiley, M. J. (1994). Body size and sex ratio in emergent stonefly nymphs (Isogenoides olivaceus: Perlodidae): variation between cohorts and populations. Canadian Fournal of Zoology 71, 1371-1375.

Harrison, J. F., Lafreniere, J.J. \& Greenlee, K. J. (2005). Ontogeny of tracheal dimensions and gas exchange capacities in the grasshopper, Schistocerca americana. Comparative Biochemistry and Physiology A 141, 372-380.

Harrison, J., Frazier, M. R., Henry, J. R., Kaiser, A., KLOK, C. J. \& Rascón, B. (2006). Responses of terrestrial insects to hypoxia or hyperoxia. Respiratory Physiology and Neurobiology 154, $4-17$.

Hawkins, B. A. (1995). Latitudinal body-size gradients for the bees of the eastern United States. Ecological Entomology 20, 195-198.

Hawkins, B. A. \& Devries, P. J. (1996). Altitudinal gradients in the body sizes of Costa Rican butterflies. Acta Oecologica 17, $185-194$.

Hawkins, B. A. \& Lawton, J. H. (1995). Latitudinal gradients in butterfly body sizes: is there a general pattern? Oecologia 102, 31-36.

Hayes, J. P. \& Shonkwiler, J. S. (2006). Allometry, antilog transformations, and the perils of prediction on the original scale. Physiological and Biochemical Zoology 79, 665-674.

Heinrich, B. \& Bartholomew, G. A. (1979). Roles of endothermy and size in inter- and intraspecific competition for elephant dung in an African dung beetle, Scarabaeus laevistriatus. Physiological Zoology 52, 484-496.

Heinze, J., Foitzik, S., Kipyatkov, V. E. \& Lopatina, E. B. (1998). Latitudinal variation in cold hardiness and body size in the boreal ant species Leptothorax acervorum (Hymenoptera: Formicidae). Entomologia Generalis 22, 305-312.

Heinze, J., Foitzik, S., Fischer, B., Wanke, T. \& Kipyatkov, V. E. (2003). The significance of latitudinal variation in body 
size in a Holarctic ant, Leptothorax acervorum. Ecography 26, 349-355.

Hirschberger, P. (1999). Larval population density affects female weight and fecundity in the dung beetle Aphodius ater. Ecological Entomology 24, 316-322.

HódAR, J. (1996). The use of regression equations for estimation of arthropod biomass in ecological studies. Acta Oecologia 17, 421-433.

Hodkinson, I. D. \& Casson, D. S. (2000). Patterns within patterns: abundance-size relationships within the Hemiptera of tropical rain forest or why phylogeny matters. Oikos 88, 509-514.

Hoffmann, A. A., Hallas, R., Sinclair, C. \& Mitrovski, P. (2001). Levels of variation in stress resistance in Drosophila among strains, local populations, and geographic regions: patterns for desiccation, starvation, cold resistance, and associated traits. Evolution 55, 1621-1630.

Hoffmann, A. A., Ratna, E., Sgrò, C. M., Barton, M., Blacket, M., Hallas, R., de Garis, S. \& Weeks, A. R. (2007). Antagonistic selection between adult thorax and wing size in field released Drosophila melanogaster independent of thermal conditions. Fournal of Evolutionary Biology 20, 2219-2227.

Holter, P. \& Scholtz, C. H. (2005). Are ball-rolling (Scarabaeini, Gymnopleurini, Sisyphini) and tunnelling scarabaeine dung beetles equally choosy about the size of ingested dung particles? Ecological Entomology 30, 700-705.

Homeny, R. H. \& Juliano, S. A. (2007). Developmental response to a seasonal time constraint: the effects of photoperiod on reproduction in the grasshopper Romalea microptera. Ecological Entomology 32, 559-566.

Honik, A. (1993). Intraspecific variation in body size and fecundity in insects: a general relationship. Oikos 66, 483-492.

Huey, R. B., Gilchrist, G. W., Carlson, M. L., Berrigan, D. \& SERRA, L. (2000). Rapid evolution of a geographic cline in size in an introduced fly. Science 287, 308-309.

Huey, R. B. \& WARD, P. D. (2005). Hypoxia, global warming, and terrestrial Late Permian extinctions. Science 308, 398-401.

Hui, C. \& Mcgeoch, M. A. (2008). Does the self-similar species distribution model lead to unrealistic predictions? Ecology 89, 2946-2952.

Hulbert, A. J. (2003). Life, death and membrane bilayers. Fournal of Experimental Biology 206, 2303-2311.

Hulbert, A. J. (2008). The links between membrane composition, metabolic rate and lifespan. Comparative Biochemistry and Physiology A 150, 196-203.

Hutchinson, G. E. \& Macarthur, R. H. (1959). A theoretical ecological model of size distributions among species of animals. American Naturalist 93, 117-125.

Imasheva, A. G., Bubli, O. A. \& Lazebny, O. E. (1994). Variation in wing length in Eurasian natural populations of Drosophila melanogaster. Heredity 72, 508-514.

Jablonski, D. (1997). Body-size evolution in Cretaceous molluscs and the status of Cope's rule. Nature 385, 250-252.

JANZEN, D. H. (1973). Sweep samples of tropical foliage insects: description of study sizes, with data on species abundances and size distributions. Ecology 54, 659-686.

Janzen, D. H., Ataroff, M., Fariñas, M., Reyes, S., Rincon, N., Soler, A., Soriano, P. \& Vera, M. (1976). Changes in the arthropod community along an elevational transect in the Venezuelen Andes. Biotropica 8, 193-203.
James, A. C., Azevedo, R. B. R. \& Partridge, L. (1995). Cellular basis and developmental timing in a size cline of Drosophila melanogaster. Genetics 140, 659-666.

James, A. C., Azevedo, R. B. R. \& Partridge, L. (1997). Genetic and environmental responses to temperature of Drosophila melanogaster from a latitudinal cline. Genetics 146, 881-890.

Johansson, F. (2003). Latitudinal shifts in body size of Enallagma cyathigerum (Odonata). Fournal of Biogeography 30, 29-34.

Johnson, J. B. \& Omland, K. S. (2004). Model selection in ecology and evolution. Trends in Ecology and Evolution 19, 101-108.

Johnson, K. P., Bush, S. E. \& Clayton, D. H. (2005). Correlated evolution of host and parasite body size: tests of Harrison's rule using birds and lice. Evolution 59, 1744-1753.

Kaiser, A., Klok, G. J., Socha, J.J., Lee, W. K., Quinlan, M. C. \& HARrison, J. F. (2007). Increase in tracheal investment with beetle size supports hypothesis of oxygen limitation on insect gigantism. Proceedings of the National Academy of Sciences of the U.S.A 104, 13198-13203.

Karan, D., Dubey, S., Moreteau, B, Parkash, R. \& David, J. R. (2000). Geographical clines for quantitative traits in natural populations of a tropical drosophilid: Zaprionus indianus. Genetica 108, 91-100.

Karan, D., Munjal, A. K., Gibert, P., Moreteau, B., Parkash, R. \& David, J. R. (1998). Latitudinal clines for morphometrical traits in Drosophila kikkawai: a study of natural populations from the Indian subcontinent. Genetics Research Cambridge 71, 31-38.

KARI, J. S. \& Huey, R. B. (2000). Size and seasonal temperature in free-ranging Drosophila subobscura. Fournal of Thermal Biology 25, $267-272$.

KASPARI, M. \& VARGO, E. L. (1995). Colony size as a buffer against seasonality: Bergmann's rule in social insects. American Naturalist 145, 610-632.

Kaspari, M. \& Weiser, M. D. (1999). The size-grain hypothesis and interspecific scaling in ants. Functional Ecology 13, 530-538.

Katzourakis, A., Purvis, A., Azmeh, S., Rotheray, G. \& Gilbert, F. (2001). Macroevolution of hoverflies (Diptera: Syrphidae): the effect of using higher-level taxa in studies of biodiversity, and correlates of species richness. Fournal of Evolutionary Biology 14, 219-227.

Kause, A., Saloniemi, I., Morin, J.-P., Haukioja, E., HАNнiмӓкі, S. \& RUономӓкі, K. (2001). Seasonally varying diet quality and the quantitative genetics of development time and body size in birch feeding insects. Evolution 55, 1992-2001.

Kemp, D. J. \& Alcock, J. (2003). Lifetime resource utilization, flight physiology, and the evolution of contest competition in territorial insects. American Naturalist 162, 290-301.

Kindlmann, P., Dixon, A. F. G. \& Dostalkova, I. (1999). Does body size optimization result in skewed body size distribution on a logarithmic scale? American Naturalist 153, 445-447.

Kingsolver, J. G. (2007). Variation in growth and instar number in field and laboratory Manduca sexta. Proceedings of the Royal Society of London B 274, 977-981.

Kingsolver, J. G. \& Pfennig, D. W. (2004). Individual-level selection as a cause of Cope's rule of phyletic size increase. Evolution 58, 1608-1612.

Kingsolver, J. G., Massie, K. R., Ragland, G.J. \& Smith, M. H. (2007). Rapid population divergence in thermal reaction 
norms for an invading species: breaking the temperature-size rule. Fournal of Evolutionary Biology 20, 892-900.

Kirkendall, L. R. \& Stenseth, N. C. (1985). On defining "breeding once". American Naturalist 125, 189-204.

Klok, C. J. \& Harrison, J. F. (2009). Atmospheric hypoxia limits selection for large body size in insects. PLoS One 4, e3876.

Koning, J. W. \& JAmieson, I. G. (2001). Variation in size of male weaponry in a harem-defence polygynous insect, the mountain stone weta Hemideina maori (Orthoptera: Anostostomatidae). New Zealand Fournal of Zoology 28, 109-117.

Kons, H. JR. (1998.). Largest Lepidopteran wingspan. http://ufbir.ifas.ufl.edu/chap32.htm

Kottelat, M., Britz, R., Hui, T. H. \& Witte, K-E. (2006). Paedocypris, a new genus of Southeast Asian cyprinid fish with a remarkable sexual dimorphism, comprises the world's smallest vertebrate. Proceedings of the Royal Society of LondonB 273, 895-899.

KozŁowski, J., Czarnoceeski, M. \& Dańko, M. (2004). Can optimal resource allocation models explain why ectotherms grow larger in cold? Integrative and Comparative Biology 44, 480-493.

KozŁowski,,J. \& GAwelczyk, A. T. (2002). Why are species' body size distributions usually skewed to the right? Functional Ecology 16, 419-432.

KozŁowski, J., Konarzewski, M. \& Gawelczyk, A. T. (2003). Cell size as a link between noncoding DNA and metabolic rate scaling. Proceedings of the National Academy of Sciences of the U.S.A 100, 14080-14085.

KozŁowski, J. \& Weiner, J. (1997). Interspecific allometries are by-products of body size optimization. American Naturalist 149, 352-380.

Krasnov, B., Ward, D. \& Shenbrot, G. (1996). Body size and leg length variation in several species of darkling beetles (Coleoptera: Tenebrionidae) along a rainfall and altitudinal gradient in the Negev Desert (Israel). Fournal of Arid Environments 34, 477-489.

Kraushaar, U. \& Blanckenhorn, W. U. (2002). Population variation in sexual selection and its effect on body size allometry in two species of flies with contrasting sexual size dimorphism. Evolution 56, 307-321.

Krüger, O. \& McGavin, G. G. (2000). Macroecology of local insect communities. Acta Oecologica 21, 21-28.

Labandeira, C. C. \& Sepkoski, J. J. (1993). Insect diversity in the fossil record. Science 261, 310-315.

Labandeira, C. C., Johnson, K. R. \& Wilf, P. (2002). Impact of the terminal Cretaceous event on plant-insect associations. Proceedings of the National Academy of Sciences of the U.S.A 99, 2061-2066.

Lawton, J. H. \& Brown, K. C. (1986). The population and community ecology of invading insects. Philosophical Transactions of the Royal Society of London B 314, 607-617.

Layalle, S., Arquier, N. \& Léopold, P. (2008). The TOR pathway couples nutrition and developmental timing in Drosophila. Developmental Cell 15, 568-577.

Lehmann, F-O., Dickinson, M. H. \& Staunton, J. (2000). The scaling of carbon dioxide release and respiratory water loss in flying fruit flies (Drosophila spp.). Fournal of Experimental Biology 203, $1613-1624$

Lehmann, T., Dalton, R., Kim, E. H., Dahl, E., Diabate, A., Dabire, R. \& Dujardin, J. P. (2006). Genetic contribution to variation in larval development time, adult size, and longevity of starved adults of Anopheles gambiae. Infection, Genetics and Evolution 6 , $410-416$.
LiebherR, J. K. (1988). Brachyptery and phyletic size increase in Carabidae (Coleptera). Annals of the Entomological Society of America 81, 157-163.

Lighton, J. R. B. (1991). Ventilation in Namib desert tenebrionid beetles: mass scaling and evidence of a novel quantized flutterphase. Fournal of Experimental Biology 159, 249-268.

Lighton, J. R. B., Quinlan, M. C. \& Feener, D. H. (1994). Is bigger better? Water balance in the polymorphic desert harvester ant Messor pergandei. Physiological Entomology 19, 325-334.

Loder, N., Blackburn, T. M. \& Gaston, K. J. (1997). The slippery slope: towards an understanding of the body size frequency distribution. Oikos 78, 195-201.

Loeschcke, V., BundgaARd, J. \& Barker, J. S. F. (2000). Variation in body size and life history traits in Drosophila aldrichi and D. buzzatii from a latitudinal cline is eastern Australia. Heredity 85, 423-433.

Lounibos, L. P. (1994). Geographical and developmental components of adult size of neotropical Anopheles (Nyssorhynchus). Ecological Entomology 19, 138-146.

Makarieva, A. M., Gorshkov, V. G. \& Li, B-L. (2004). Ontogenetic growth: models and theory. Ecological Modelling 176, 15-26.

Makarieva, A. M., Gorshrov, V. G. \& Li, B-L. (2005). Temperature-associated upper limits to body size in terrestrial poikilotherms. Oikos 111, 425-436.

Mangel, M. \& Munch, S. B. (2005). A life-history perspective on short- and long-term consequences of compensatory growth. American Naturalist 166, E155-E176.

Marcondes, G. B., Lozovei, A. L., Falqueto, A., Brazil, R. P., Galati, E. A. B., Aguiar, G. M. \& Souza, N. A. (1999). Influence of altitude, latitude and season of collection (Bergmann's Rule) on the dimensions of Lutzomyia intermedia (Lutz \& Neiva, 1912) (Diptera, Psychodidae, Phlebotominae). Memorias do Instituto Oswaldo Cruz, Rio de Faneiro 94, 693-700.

Margraf, N., Gotthard, K. \& Rahier, M. (2003). The growth strategy of an alpine beetle: maximization or individual growth adjustment in relation to seasonal time horizons? Functional Ecology 17, 605-610.

Masaki, S. (1967). Geographic variation and climatic adaptation in a field cricket (Orthopetra: Gryllidae). Evolution 21, 725-741.

Masaki, S. (1978). Climatic adaptation and species status in the lawn ground cricket. II. Body size. Oecologia 35, 343-356.

MASAKI, S. (1996). Geographical variation of life cycle in crickets (Ensifera: Grylloidea). European Fournal of Entomology 93, 281-302.

Maurer, B. A., Brown, J. H. \& Rusler, R. D. (1992). The micro and macro in body size evolution. Evolution 46, 939-953.

May, R. M. (1978). The dynamics and diversity of insect faunas. In Diversity of Insect Faunas (eds. L. A. Mound \& N. Waloff), pp. 188-204, Blackwell Scientific Publications, Oxford.

McGill, B. J. (2003). Does Mother Nature really prefer rare species or are log-left-skewed SAD's a sampling artefact? Ecology Letters 6, 766-773.

Mercer, R. D., Gabriel, A. G. A., Barendse, J., Marshall, D. J. \& Chown, S. L. (2001). Invertebrate body sizes from Marion Island. Antarctic Science 13, 135-143.

Miller, P. L. (1966). The supply of oxygen to the active flight muscles of some large beetles. Fournal of Experimental Biology 45, 285-304.

Millien, V., Lyons, S. K., Olson, L., Smith, F. A., Wilson, A. B. \& Yom-Tov, Y. (2006). Ecotypic variation in the context 
of global climate change: revisiting the rules. Ecology Letters 9, 853-869.

Mirth, G. K. \& Riddiford, L. M. (2007). Size assessment and growth control: how adult size is determined in insects. BioEssays 29, 344-355.

MoczeK, A. P. \& Nijhout, H. F. (2003). Rapid evolution of a polyphenic threshold. Evolution and Development 5, 259-268.

Molumby, A. (1997). Why make daughters larger? Maternal sex-allocation and sex-dependent selection for body size in a mass-provisioning wasp, Trypoxylon politum. Behavioral Ecology 8, 279-287.

Moreteau, B., Gibert, P., Petavy, G., Moreteau, J. C., HueY, R. B. \& DAvid, J. R. (2003). Morphometrical evolution in a Drosophila clade: the Drosophila obscura group. Fournal of Zoological Systematics and Evolutionary Research 41, 64-71.

Morse, D. R., Lawton, J. H., Dodson, M. M. \& Williamson, M. H. (1985). Fractal dimension of vegetation and the distribution of arthropod body lengths. Nature 314, 731-733.

Morse, D. R., Stork, N. E. \& Lawton, J. H. (1988). Species number, species abundance and body length relationships of arboreal beetles in Bornean lowland rain forest trees. Ecological Entomology 13, 25-37.

Mousseau, T. A. \& RofF, D. A. (1989). Adaptation to seasonality in a cricket: patterns of phenotypic and genotypic variation in body size and diapause expression along a cline in season length. Evolution 43, 1483-1496.

Moya-Laraño, J., El-Sayyid, M. E. T. \& Fox, C. W. (2007). Smaller beetles are better scramble competitors at cooler temperatures. Biology Letters 3, 475-478.

MyburGH, E. (2001.). The influence of developmental temperature on the survival of adult Simulium chutteri (Diptera: Simuliidae). M.Sc. Thesis, University of Pretoria, South Africa.

Nee, S. \& Lawton, J. H. (1996). Ecology - body-size and biodiversity. Nature 380, 672-673.

Nijhout, H. F. (1975). Threshold size for metamorphosis in the tobacco hornworm, Manduca sexta (L.). Biological Bulletin 149, 568-579.

Nijhout, H. F. (1994). Insect Hormones. Princeton University Press, Princeton.

Nijhout, H. F. (2003). The control of body size in insects. Developmental Biology 261, 1-9.

Nijhout, H. F., Davidowitz, G. \& Roff, D. A. (2006). A quantitative analysis of the mechanism that controls body size in Manduca sexta. Fournal of Biology 5(16): 1-15.

Novotný, V. \& Kindlmann, P. (1996). Distribution of body sizes in arthropod taxa and communities. Oikos 75, 75-82.

Novotný, V. \& Wilson, M. R. (1997). Why are there no small species among xylem-sucking insects? Evolutionary Ecology 11, 419-437.

Nylin, S. \& GotThard, K. (1998). Plasticity in life-history traits. Annual Review of Entomology 43, 63-83.

Nylin, S., Gotthard, K. \& Wiklund, C. (1996). Reaction norms for age and size at maturity in Lasiommata butterflies: predictions and tests. Evolution 50, 1351-1358.

Nylin, S. \& SväRD, L. (1991). Latitudinal patterns in the size of European butterflies. Holarctic Ecology 14, 192-202.

Oldham, S., Böhni, R., Stocker, H., Brogiolo, W. \& Hafen, E. (2000). Genetic control of size in Drosophila. Philosophical Transactions of the Royal Society of London B 355, 945-952.
Olson, V. A., Davies, R. G., Orme, C. D. L., Thomas, G. H., Meiri, S., Blackburn, T. M., Gaston, K. J., Owens, I. P. F. \& BennetT, P. M. (2009). Global biogeography and ecology of body size in birds. Ecology Letters 12, 249-259.

Orme, G. D. L., Isaac, N. J. B. \& Purvis, A. (2002). Are most species small? Not within species-level phylogenies. Proceedings of the Royal Society of London B 269, 1279-1287.

PAlmer, M. (2002). Testing the 'island rule' for a tenebrionid beetle (Coleoptera, Tenebrionidae). Acta Oecologia 23, 102-107.

PARK, O. (1949). Application of the converse Bergmann principle to the carabid beetle, Dicaelus purpuratus. Physiological Zoology 22, 359-372.

Parker, J. \& Johnston, L. A. (2006). The proximate determinants of insect size. Fournal of Biology 5(15): 1-4.

Parker, G. A. \& Simmons, L. W. (1994). Evolution of phenotypic optima and copula duration in dungflies. Nature 370, 53-56.

Peat, J., Darvill, B., Ellis, J. \& Goulson, D. (2005). Effects of climate on intra- and inter-specific size variation in bumblebees. Functional Ecology 19, 145-151.

Plaistow, S. J., Tsuchida, K., Tsubaki, Y. \& Setsuda, K. (2005). The effect of a seasonal time constraint on development time, body size, condition, and morph determination in the horned beetle Allomyrina dichotoma L. (Coleoptera: Scarabaeidae). Ecological Entomology 30, 692-699.

Porter, E. E. \& Hawkins, B. A. (2001). Latitudinal gradients in colony size for social insects: termites and ants show different patterns. American Naturalist 157, 97-106.

Pörtner, H. O. (2001). Climate change and temperaturedependent biogeography: oxygen limitation of thermal tolerance in animals. Naturwissenschaften 88, 137-146.

Powell, S. \& Franks, N. R. (2006). Ecology and the evolution of worker morphological diversity: a comparative analysis with Eciton army ants. Functional Ecology 20, 1105-1114.

RAscón, B. \& Harrison, J. F. (2005). Oxygen partial pressure effects on metabolic rate and behavior of tethered flying locusts. Fournal of Insect Physiology 51, 1193-1199.

Read, A. F. \& Harvey, P. H. (1989). Life history differences among the eutherian radiations. Fournal of Zoology London 219, 329-353.

Reim, G., Teuschl, Y. \& Blanckenhorn, W. U. (2006). Sizedependent effects of temperature and food stress on energy reserves and starvation resistance in yellow dung flies. Evolutionary Ecology Research 8, 1215-1234.

Rivero, A. \& West, S. A. (2002). The physiological costs of being small in a parasitic wasp. Evolutionary Ecology Research 4, 407-420.

Roces, F. \& Lighton, J. R. B. (1995). Larger bites of leaf-cutting ants. Nature 373, 392-393.

Röder, G., Rahier, M. \& Naisbit, R. E. (2008). Counterintuitive developmental plasticity induced by host quality. Proceedings of the Royal Society of London B 275, 879-885.

Rodrigues, D. \& Moreira, G. R. P. (2004). Seasonal variation in larval host plants and consequences for Heliconius erato (Lepidoptera: Nymphalidae) adult body size. Austral Ecology 29, 437-445.

RofF, D. (1980). Optimizing development time in a seasonal environment: the 'ups and downs' of clinal variation. Oecologia 45, 202-208.

RoFf, D. (1981). On being the right size. American Naturalist 118, 405-422. 
Roff, D. A. (2001). Age and size at maturity. In Evolutionary Ecology. Concepts and Case Studies, (eds. C. W. Fox, D. A. Roff \& D. J. Fairbairn), pp. 99-112. Oxford University Press, Oxford.

Roff, D. A. (2002). Life History Evolution. Sinauer Associates, Sunderland.

Rogers, D. J. \& Randolph, S. E. (1991). Mortality rates and population density of tsetse flies correlated with satellite imagery. Nature 351, 739-741.

Rourke, B. C. (2000). Geographic and altitudinal variation in water balance and metabolic rate in a California grasshopper, Melanoplus sanguinipes. Fournal of Experimental Biology 203, 2699-2712.

Rust, R. (2006). Latitudinal variation in the size and developmental parameters of the Alkali bee, Nomia melanderi (Hymenoptera: Halictidae) Fournal of the Kansas Entomological Society 79, 239-248.

Ruttner, F., Elmi, M. P. \& Fuchs, S. (2000). Ecoclines in the Near East along 36 degrees $\mathrm{N}$ latitude in Apis mellifera $\mathrm{L}$. Apidologie 31, 157-165.

Schmitz, A. \& Harrison, J. F. (2004). Hypoxic tolerance in airbreathing invertebrates. Respiratory Physiology and Neurobiology 141, 229-242.

SCriber, J. M. (2002). Latitudinal and local geographic mosaics in host plant preferences as shaped by thermal units and voltinism in Papilio spp. (Lepidoptera). European Fournal of Entomology 99, 225-239.

Scriber, J. M. \& Lederhouse, R. C. (1992). The thermal environment as a resource dictating geographic patterns of feeding specialization of insect herbivores. In Effects of Resoure Distribution on Animal-Plant Interactions (eds. M. D. Hunter, T. Ohgushi, and P. W. Price), pp. 429-466, Academic Press, San Diego.

SeHnal, F. (1985). Growth and life cycles. In Comprehensive Physiology, Biochemistry, and Pharmacology of Insects Vol. 2 (eds. G. A. Kerkut and L. I. Gilbert), pp. 1-86, Pergamon Press, Oxford.

Sequiera, R. \& Mackauer, M. (1993). Seasonal variation in body size and offspreing sex ratio in field populations of the parasitoid wasp, Aphidius ervi (Hymenoptera: Aphidiidae). Oikos 68, 340-346.

Shafiei, M., Moczek, A. P. \& Nijhout, H. F. (2001). Food availability controls the onset of metamorphosis in the dung beetle Onthophagus taurus (Coleoptera: Scarabaeidae). Physiological Entomology 26, 173-180.

Shear, W. A. \& Kukalová-Peck, J. (1990). The ecology of Palaeozoic terrestrial arthropods: the fossil evidence. Canadian Journal of Zoology 68, 1807-1834.

Shingleton, A. W., $\quad$ Frankino, W. A., Flatt, T., Nijhout, H. F. \& Emlen, D. J. (2007). Size and shape: the developmental regulation of static allometry in insects. BioEssays 29, 536-548.

Shingleton, A. W., Mirth, G. K. \& Bates, P. W. (2008). Developmental model of static allometry in holometabolous insects. Proceedings of the Royal Society of London B 275, 1875-1885.

Shorrocks, B., Marsters, J., Ward, I. \& Evennett, P. J. (1991). The fractal dimensions of lichens and the distribution of arthropod body lengths. Functional Ecology 5, 457-460.

Siemann, E., Haarstad, J. \& Tilman, D. (1999). Dynamics of plant and arthropod diversity during old field succession. Ecography 22, 406-414.

Smith, F. A., Brown, J. H., Haskell, J. P., Lyons, S. K., Alroy, J., Charnov, E. L., Dayan, T., EnQuist, B. J.,
Ernest, S. K. M., Hadly, E. A., Jones, K. E., Kaufman, D. M., Marquet, P. A., Maurer, B. A., Niklas, K. J., Porter, W. P., Tiffney, B. H. \& Willig, M. R. (2004). Similarity of mammalian body size across the taxonomic hierarchy and across space and time. American Naturalist 163, 672-691.

Smith, R. J., Hines, A., Richmond, S., Merrick, M., Drew, A. \& FARgo, R. (2000). Altitudinal variation in body size and population density of Nicrophorus investigator (Coleoptera: Silphidae). Environmental Entomology 29, 290-298.

Stalker, H. D. \& Carson, H. L. (1948). An altitudinal transect of Drosophila robusta Sturtevant. Evolution 2, 295-305.

Steenkamp, H. E. \& Chown, S. L. (1996). Influence of dense stands of an exotic tree, Prosopis glandulosa Benson, on a savanna dung beetle (Coleoptera: Scarabaeinae) assemblage in southern Africa. Biological Conservation 78, 305-311.

Steffan-Dewenter I. \& Tscharntke, T. (1997). Early succession of butterfly and plant communities on set-aside fields. Oecologia 109, 294-302.

Steigenga, M.J. \& Fischer, K. (2007). Within- and betweengeneration effects of temperature on life-history traits in a butterfly. Fournal of Thermal Biology 32, 396-405.

Stillwell, R. G. \& Fox, G. W. (2005). Complex patterns of phenotypic plasticity: interactive effects of temperature during rearing and oviposition. Ecology 86, 924-934.

Stillwell, R. C., Morse, G. E. \& Fox, C. W. (2007). Geographic variation in body size and sexual size dimorphism of a seed-feeding beetle. American Naturalist 170, 358-369.

Stoks, R., De Block, M. \& Mcpeek, M. A. (2006a). Physiological costs of compensatory growth in a damselfly. Ecology 87, $1566-1574$.

Stoks, R., De Block, M., Van Dooerslaer, W. W. \& Rolff, J. $(2006 b)$. Time constraints mediate predator-induced plasticity in immune function, condition, and life history. Ecology 87, 809-815.

Stone, G. N. (1993). Thermoregulation in four species of tropical solitary bees: the roles of size, sex and altitude. Fournal of Comp Physiol B 163, 317-326.

Stone, G. N. (1994). Activity patterns of females of the solitary bee Anthophora plumipes in relation to temperature, nectar supplies and body size. Ecological Entomology 19, 177-189.

Stone, G. N., Loder, P. M.J. \& Blackburn, T. M. (1995). Foraging and courtship behaviour in males of the solitary bee Anthophora plumipes (Hymenoptera: Anthophoridae): thermal physiology and the roles of body size. Ecological Entomology 20, 169-183.

Storch, D., ŠIzling, A. L., Reif, J., Polechová, J., Šizlingová, E. \& Gaston, K. J. (2008). The quest for a null model for macroecological patters: geometry of species distributions at multiple spatial scales. Ecology Letters 11, 771-784.

Strobbe, F. \& SToks, R. (2004). Life history reaction norms to time constraints in a damselfly: differential effects on size and mass. Biological Journal of the Linnean Society 83, 187-196.

Tammaru, T., Nylin, S., Ruohomäki, K. \& Gotthard, K. (2004). Compensatory responses in lepidopteran larvae: a test of growth rate maximisation. Oikos 107, 352-362.

Tantawy, A. O. (1964). Studies on natural populations of Drosophila. III. Morphological and genetic differences of wing length in Drosophila melanogaster and D.simulans in relation to season. Evolution 18, 560-570. 
Taylor, B. W., Anderson, C. R. \& Peckarsky, B. L. (1998). Effects of size at metamorphosis on stonefly fecundity, longevity, and reproductive success. Oecologia 114, 494-502.

Teder, T. \& Tammaru, T. (2005). Sexual size dimorphism within species increases with body size in insects. Oikos 108, 321-334.

Teder, T., Tammaru, T. \& Esperk, T. (2008). Dependence of phenotypic variance in body size on environmental quality. American Naturalist 172, 223-232.

Telfer, M. G. \& Hassall, M. (1999). Ecotypic differentiation in the grasshopper Chorthippus brunneus: life history varies in relation to climate. Oecologia 121, 245-254.

Teuschl, Y., Reim, C. \& Blanckenhorn, W. U. (2007). Correlated responses to artificial body size selection in growth, development, phenotypic plasticity and juvenile viability in yellow dung flies. Fournal of Evolutionary Biology 20, 87-103.

Tompkins, D. M. \& Clayton, D. H. (1999). Host resources govern the specificity of swiftlet lice: size matters. Fournal of Animal Ecology 68, 489-500.

Ulrich, W. (2004). Allometric ecological distributions in a local community of Hymenoptera. Acta Oecologica 25, 179-186.

Van Der Have, T. M. \& De Jong, G. (1996). Adult size in ectotherms: temperature effects on growth and differentiation. Fournal of Theoretical Biology 183, 329-340.

Vessby, K. (2001). Habitat and weather affect reproduction and size of the dung beetle Aphodius fossor. Ecological Entomology 26, 430-435.

Walters, R. J. \& Hassall, M. (2006). The temperature-size rule in ectotherms: may a general explanation exist after all? American Naturalist 167, 510-523.

Ward, P., Labandeira, C., Laurin, M. \& Berner, R. A. (2006). Confirmation of Romer's Gap as a low oxygen interval constraining the timing of initial arthropod and vertebrate terrestrialization. Proceedings of the National Academy of Sciences of the U.S.A 103, 16818-16822.

Warren, M., McGeoch, M. A., Nicolson, S. W. \& Chown, S. L. (2006). Body size patterns in Drosophila inhabiting a mesocosm: interactive effects of spatial variation in temperature and abundance. Oecologia 149, 245-255.

Weeks, A. R., Mckechnie, S. W. \& Hoffmann, A. A. (2002). Dissecting adaptive clinal variation: markers, inversions and size/stress associations in Drosophila melanogaster from a central field population. Ecology Letters 5, 756-763.

White, G. R., Blackburn, T. M., Terblanche, J. S., Marais, E., Gibernau, M. \& Chown, S. L. (2007). Evolutionary responses of discontinuous gas exchange in insects. Proceedings of the National Academy of Sciences of the U.S.A 104, 8357-8361.

White, E. P., Ernest, S. K. M., Kerkhoff, A.J. \& ENQUist, B. J. (2007). Relationships between body size and abundance in ecology. Trends in Ecology and Evolution 22, 323-330.

Wilf, P., Labandeira, C. G., Johnson, K. R. \& Ellis, B. (2006). Decoupled plant and insect diversity after the endcretaceous extinction. Science 313, 1112-1115.

Williams, D. M. (2001.). Largest. http://ufbir.ifas.ufl.edu/ chap30.htm

Woods, H. A., Fagan, W. F., Elser, J.J. \& Harrison, J. F. (2004). Allometric and phylogenetic variation in insect phosphorous content. Functional Ecology 18, 103-109.

Wootton, R. J. \& Kukalová-Peck, J. (2000). Flight adaptations in Palaeozoic Palaeoptera (Insecta). Biological Reviewes 75, 129-167.

Yuval, B., Wekesa, J. A., Lemenager, D., Kauffman, E. E. \& WAshino, R. K. (1993). Seaonal variation in body size of mosquitoes (Diptera: Culicidae) in a rice culture agroecosystem. Environmental Entomology 22, 459-463. 